\title{
Pharmacological Effect of Quercetin in Hypertension and Its Potential Application in Pregnancy-Induced Hypertension: Review of In Vitro, In Vivo, and Clinical Studies
}

\author{
Marcin Ożarowski (D), ${ }^{1}$ Przemysław L. Mikołajczak (D), \\ Radosław Kujawski, ${ }^{2}$ Karolina Wielgus, ${ }^{1}$ Andrzej Klejewski, ${ }^{3,4}$ \\ Hubert Wolski, ${ }^{5,6}$ and Agnieszka Seremak-Mrozikiewicz ${ }^{1,5,7}$ \\ ${ }^{1}$ Institute of Natural Fibres and Medicinal Plants, Wojska Polskiego 71b, 60-630 Poznań, Poland \\ ${ }^{2}$ Department of Pharmacology, Poznań University of Medical Sciences, Rokietnicka, 5a, 60-806 Poznań, Poland \\ ${ }^{3}$ Department of Nursing, Poznan University of Medical Sciences, Poznań, Poland \\ ${ }^{4}$ Department of Obstetrics and Women's Diseases, Poznan University of Medical Sciences, Poznań, Poland \\ ${ }^{5}$ Department of Perinatology and Women's Diseases, Poznan University of Medical Sciences, Polna 33, 60-535 Poznań, Poland \\ ${ }^{6}$ Division of Gynecology and Obstetrics, Podhale Multidisciplinary Hospital, Nowy Targ, Poland \\ ${ }^{7}$ Laboratory of Molecular Biology, Poznan University of Medical Sciences, Polna 33, 60-535 Poznań, Poland
}

Correspondence should be addressed to Marcin Ożarowski; mozarowski@poczta.onet.pl

Received 31 August 2018; Revised 25 October 2018; Accepted 8 November 2018; Published 2 December 2018

Academic Editor: Deborah A. Kennedy

Copyright (C) 2018 Marcin Ożarowski et al. This is an open access article distributed under the Creative Commons Attribution License, which permits unrestricted use, distribution, and reproduction in any medium, provided the original work is properly cited.

\begin{abstract}
Since improving maternal and child health is a public health priority worldwide, the main aim of treatment of hypertension in pregnant women is to prevent complications during pregnancy, labor, and postpartum. In consequence, much attention is paid to the use of antihypertensive drugs that can be used safely during pregnancy. Several side effects of methyldopa, which is currently the most commonly used antihypertensive drug in pregnant women, mean that the search for an effective and safe alternative still continues. Flavonoid compounds present in medicinal plants, vegetables, and fruits may be a promising source of new drugs. In this aspect, quercetin, a well-known flavonoid due to its antihypertensive action, may be considered a prototype for safe antihypertensive drugs. This review focuses on the selective activity of quercetin. Based on recent studies, a few problems were discussed, including (1) pathology of pregnancy-induced hypertension; (2) search for new pharmacological treatments of pregnancy-induced hypertension; (3) issues with the use of herbal extracts during pregnancy; (4) flavonoids as natural active chemical compounds; (5) quercetin: its action during pregnancy, in vitro and in vivo pharmacological activities, clinical trials, and meta-analysis; (6) quercetin intake during pregnancy; (7) other natural compounds tested during pregnancy; (8) potential problems with the use of quercetin; (9) safety profile of quercetin. Various studies have shown a beneficial effect of quercetin on vascular endothelial function and its antioxidative and anti-inflammatory activity on cellular and tissue level. It is known that in animal models quercetin affects positively the development of embryo, fetus, and placenta. Because this flavonoid did not have teratogenic and abortive effect, it is generally recognized as safe. For this reason it should be appreciated and studied in the aspect of its potential use in the prevention and treatment of pregnancyinduced hypertension among women in this risk group.
\end{abstract}

\section{Pathology of Pregnancy-Induced Hypertension}

The increasing number of patients suffering from cardiovascular diseases, including hypertension being often developed during pregnancy, indicates the need for innovative strategies for more effective prevention and treatment [1].

Hypertensive disorders during pregnancy are classified into 4 categories, as per National High Blood Pressure Education Program Working Group on High Blood Pressure 
in Pregnancy: (1) chronic hypertension, (2) preeclampsiaeclampsia, (3) preeclampsia superimposed on chronic hypertension, and (4) gestational hypertension (transient hypertension of pregnancy or chronic hypertension identified in the latter half of pregnancy) [1]. This terminology is more precise and thus it is preferred over the older yet more commonly used term pregnancy-induced hypertension (PIH) [2].

Preeclampsia (ICD-10 code 014) is defined as a complication of pregnancy characterized by a complex of symptoms including maternal hypertension and proteinuria with or without pathological edema. Preeclampsia is the most dangerous complication during pregnancy because of hypertrophy and premature detachment of the placenta, and intrauterine fetal death. Preeclampsia usually occurs after the 20th week of gestation, but may develop before this time in the presence of trophoblastic disease [3]. In detail, preeclampsia was defined as high blood pressure $(\geq 140 \mathrm{mmHg}$ systolic or $\geq 90 \mathrm{mmHg}$ diastolic, or increases of $30 \mathrm{mmHg}$ systolic or $15 \mathrm{mmHg}$ diastolic from the baseline on at least two occasions, six or more hours apart) that develops from the 20th gestational week in a previously normotensive woman, with proteinuria (one 24-hour urine collection with a total protein excretion of at least $300 \mathrm{mg} / \mathrm{l})[4,5]$. Preeclampsia is one of the major causes of maternal and fetal mortality worldwide with more than 75,000 maternal death cases per year [6-8]. Complications of severe hypertension in pregnant women may include intracerebral bleeding, cardiac problems, and placental dysfunction causing several other problems [9]. The etiology of preeclampsia remains yet not fully known. One of the hypotheses concerns placental endothelial cells dysfunction [10]. Changes in uteroplacental unit resulting in PIH may be also caused by the influence of reninangiotensin system disturbances, activity of coagulation cascade elements, influence of oxidative stress, or improper inflammatory reactions [11]. Hence, the attention is focused on the endothelial damage of spiral arteries leading to the decreased concentration of vasodilators (prostacyclin, nitric oxide) and increased level of vasoconstrictors (thromboxane, endothelin-1), as well as on the explanation of impaired function of placental endothelial nitric oxide synthase.

Proper blood flow in the uteroplacental unit is a result of the presence of vasoactive humoral factors, such as nitric oxide, a crucial regulator of the flow in the uteroplacental unit $[11,12]$. In case of PIH, a very low nitric oxide production leads to impaired vasodilatation. Thus, PIH development is probably due to imbalance between placental vasoconstrictors and vasodilators [13]. Endothelial nitric synthase expressed and localized in uteroplacental endothelium and trophoblasts is suggested to play an important role in the regulation of maternal and fetoplacental hemodynamics during pregnancy. The interaction between nitric oxide, forms of nitric oxide synthase, and endothelin-1 in fetoplacental unit is strongly associated with and regulates placental blood flow in normal pregnancies and was found to be disturbed in hypertensive women [14]. Any changes in endothelin-1 activity or quantity may influence the proper development of fetoplacental unit leading to PIH. Its pathogenesis is explained in such case by endothelium damage of spiral arteries during trophoblast invasion to the vessel wall $[15,16]$. In PIH trophoblast invasion is limited only to decidual part of spiral arteries leading to placental anoxia and endothelial damage. These changes are evoked by the imbalance of vasodilators and vasoconstrictors. During such pathological process plasma levels of thromboxane A2 and endothelin-1 are observed to increase while nitric oxide levels are observed to decrease. The impaired balance between vasoactive factors, especially disturbances in endothelin-1 that is secreted early in pregnancy, intensifies during the second half of pregnancy [17-19]. Recently, multiple studies report that endothelin1 levels are increased in PIH and that there is a positive correlation between endothelin-1 and severity of symptoms [20-22].

Pregnancy-induced hypertension is a state of extremely increased oxidative stress due to the decrease of antioxidant capacity. Oxidative stress as an imbalance between free radical generation and antioxidant defense is a recognized key factor in the pathogenesis of many diseases including obstetrical complications. One of the consequences of increased oxidative stress is impairment of placental blood flow, intrauterine hypoxia of the fetus, and disturbance in transfer of oxygen [44]. It is worth remarking that $\mathrm{PIH}$ is a multisystem disorder, which involves not only altered homeostasis of oxidants-antioxidants but also inflammatory process and endothelial dysfunction. Moreover, women are more likely to have increased oxidative stress during pregnancy, which may lead to adverse neonatal outcomes [45].

The etiology of PIH is believed to be associated with a systemic inflammatory response but few inflammatory markers are currently available to predict that state. It is suggested that women display an exaggerated inflammatory response in the course of pregnancy due to an unbalanced regulation of innate and adaptive immune responses. It is also thought that dysregulation of endogenous protective pathways might be associated with PIH etiology. Inflammation is an active process regulated by various mediators that control key cellular events to restore tissue homeostasis. Impaired resolution of inflammation probably plays vital role in the development of chronic inflammatory diseases and $\mathrm{PIH}$ is believed to be one of them [46].

In recent years, there has been progress in the knowledge of molecular mechanisms responsible for cellular and tissuespecific processes during pregnancy-induced hypertension. In addition to the aforementioned factors, some specific mediators that play a significant role have been identified; $\mathrm{PIH}$ is associated with impaired perfusion of placenta, which leads to altered secretion of markers of angiogenesis [8]. Change in endometrial levels of many angiogenic growth factors has been observed in PIH, including vascular endothelial growth factor A (VEGF-A), mRNAs encoding VEGF-C, placental growth factor (PlGF), the angiopoietins, angiopoietin 1(Ang1) and Ang2, and the receptors VEGFR-3 (Flt-4), Tie 1, Tie $2[47,48]$. Finally, it was shown in experimental animal models of PIH that the placental growth factor (PlGF) is both a biomarker and a potential therapeutic option. PlGF is a member of the vascular endothelial growth factor (VEGF) family, is predominantly expressed in the placenta, and plays a key role in the promotion of development and maturation 
of placental vascular system. It is known that serum and urinary concentration of PlGF is decreased in women with preeclampsia $[49,50]$. Hentschke et al. [50] observed a $62 \%$ reduction of PlGF levels in pregnant women with $\mathrm{PIH}$. Rocha et al. [51] showed that low maternal plasma PlGF was associated with earlier delivery and adverse pregnancy outcomes while levels below $<40-50 \mathrm{pg} / \mathrm{ml}$ were associated with exceptionally high risk of intrauterine fetal death.

Other growth factors also play a role. It has been demonstrated by Zhou et al. [47] that several VEGF family members regulate cytotrophoblast survival and that expression of a subset of family members is dysregulated in severe forms of PIH. Relevant to PIH are also tumor necrosis factor alpha (TNF-alpha) stimulated by TNF-alpha receptor (TNFR1) (and by conditions of depleted oxygen) [52], epidermal growth factor (EGF), platelet-derived growth factor (PDGF), or insulin-like growth factor-1 (IGF-1) [49, 53, 54]. Previously, it was observed that elevated serum concentration of basic fibroblast growth factor (bFGF) was associated with mild hypertensive disorders in pregnancy [55]. Further studies have confirmed the participation of growth factors in the pathogenesis of PIH $[8,56,57]$ and in the etiology of intrauterine growth restriction [58].

\section{Searching for New Pharmacological Strategies for Pregnancy-Induced Hypertension}

The main aim of treatment of hypertension in pregnant women is to prevent complications throughout pregnancy, during childbirth and postpartum. Much attention is paid to the use of antihypertensive drugs from across different pharmacological groups. Yet, from pharmacokinetic and pharmacodynamic point of view, we should be aware of special conditions for drugs use during pregnancy, namely, the presence of an additional compartment, i.e., the fetalplacental unit $[9,59]$. Therefore, the impact of drugs on the fetus must be considered.

Drug treatment options in PIH are limited because some antihypertensive drugs, such as ACE inhibitors and angiotensin II receptor (AT1) antagonists (sartans), showed teratogenic effects. Methyldopa belongs to first-line treatment of PIH. It is taken per os and is well absorbed. It crosses the placenta reaching fetal serum concentrations similar to those in the mother. The onset of action is delayed for 1-2 hours after intravenous administration and 4-6 hours after oral administration; it is effective for 6-12 hours [9]. Methyldopa belongs to the group of medicines acting on central nervous system to evoke depression in the cardiovascular system [60]. Numerous reports have confirmed the high usefulness of this drug for reducing blood pressure in pregnant women, both with chronic hypertension and pregnancy-induced hypertension [60]. The reduction of blood pressure in pregnant women with hypertension using methyldopa can have a significant positive impact on the uteroplacental circulation, which improves the provision of oxygen and nutrients to the developing fetus [59, 61, 62].
Many other groups are used in the treatment of PIH, including beta blockers like metoprolol or labetalol, dihydropyridine derivatives like nitrendipine or nifedipine, and other vasodilators such as hydralazine and dihydralazine. Yet, methyldopa remains a mainstay of PIH treatment mostly due to reported uteroplacental perfusion stability and fetal hemodynamics $[63,64]$. However, treatment of PIH remains challenging since methyldopa has some adverse side effects, such as hepatotoxicity [65], and may be hard to tolerate for evoking dizziness, depression, headache, etc. [66]. Generally, the use of methyldopa and labetalol has increased in recent years while the use of other antihypertensive drugs has declined [64]. Most importantly, angiotensinconverting enzyme (ACE) inhibitors as well as angiotensinreceptor blockers should be avoided in the second and third trimesters of pregnancy because of their adverse effects on fetal development. Pregnant women treated with ACE inhibitors often develop oligohydramnios, which may be caused by decreased fetal renal function $[5,63]$. Also diuretics are inappropriate for their lack of efficacy in the prevention of PIH and for the risk of more nausea and vomiting [67]. For this reason, quercetin may be considered as a potential alternative method in prevention and treatment of pregnantinduced hypertension. More importantly, quercetin may have a potential application as an adjuvant therapy together with methyldopa to increase effectiveness of therapy. Therefore, administration of quercetin may be complementary and provide support for patients treated with methyldopa. This way doses of methyldopa, hence its adverse effects, could be diminished. By analogue, similar result could be expected from combining quercetin with other antihypertensive drugs (i.e., nitrendipine, nifedipine, labetalol, metoprolol, hydralazine and dihydralazine). However, additional studies should be carried out to provide evidence of such positive pharmacological interaction. The search for active substances derived from vegetables and medicinal plants is well-established in science since many medicinal discoveries come from natural sources. One of the sources of new drugs is medicinal plants, which are known to contain flavonoids with a proven antihypertensive effect $[68,69]$.

\section{The Issue of the Use of Herbal Extracts during Pregnancy}

Application of herbal products is one of the methods in complementary and alternative medicine [70]. Recently, several multinational studies have been carried out to determine prevalence of herbal medicine use in pregnancy. These studies allow us to deduce that an increasing number of women put their own and their unborn children's health at risk due to lack of knowledge about phytochemical properties or adequate use of herbal medicinal products, as well as lack of communication with healthcare provider [71-74]. There has been a continuous increase of interest in the use of herbal products but the available recommendations are very often controversial or contradictory [9]. The prevalence of herbal medicine use in pregnancy ranges from $7 \%$ to $55 \%$ across different geographical, social, and cultural settings and is 
different across ethnic groups $[70,75]$. Herbal products are very often preferred over prescription medications due to the belief that herbs are safer for the fetus than modern medicine $[71,72]$. Nonetheless, according to Bruno et al. [76], because the side effects and teratogenic potential of most herbal medicines are poorly understood, herbal dietary supplements are often mistaken as harmless unless proven otherwise. It is well known that plant extracts and other herbal products are complex mixtures, and their action is a result of summation of activities of several chemical components. It should be stressed that standardization of the extract does not guarantee safety of use during pregnancy [76]. It is due to the fact that while the main compound has no side effect on the fetus, often the other adjuncts to the herbal product mixture, although occurring in small amounts, may adversely affect the developing fetus. Moreover, it should be noted that plants interact with their environment. Thus, plants' chemical composition may be quite diverse [77]. Also, manufacturing process of herbal medicinal products is very complex because it encompasses nonstandardized processes like cultivation of plants, obtaining vegetable raw material from various parts of the world, preparing of extract, and producing a product in accordance with local guidelines of good manufacturing practice. It is known that each stage of such herbal drug development may affect the final composition of the herbal medicine, which is of paramount importance in light of safety of use in pregnant women [77]. Although there is clinical evidence of safe use of certain plant extracts during pregnancy, clinical data are often inconclusive due to small sample sizes, ethical reservations, or incomplete study designs [76]. Therefore, it can be concluded that using pure chemical compounds of natural origin (for example flavonoids) would be a far safer option for pregnancy and for the developing embryo or fetus since pure compounds do not contain additional substances and their precise dosage is easier. Furthermore, application of a single flavonoid allows straightforward studying of its mechanism of action and its influence on various targets during pathological processes in pregnancy.

Epidemiological and intervention studies strongly suggest that flavonoid intake has beneficial effects on vascular health [78]. Several flavonoids were investigated in various models of vascular disorders showing their antioxidant properties and vasodilator effect, as well as antiinflammatory, antiatherogenic, and antithrombotic effect [79-82]. However, evaluation of the vascular function of dietary flavonoids remains difficult due to lack of information on their bioavailability, biotransformation, or bioaccumulation [78], especially during pregnancy. Moreover, biodynamics in the vascular system during pregnancy should be taken into account to estimate the antihypertensive effect of dietary flavonoids. Generally, the use of natural substances is a scientific and therapeutic challenge due to specific physiological and pathological changes occurring during pregnancy.

\section{Flavonoids as Active Natural Chemical Compounds}

Plant flavonoids and their conjugates belong to a large family of natural phenylpropanoid-derived polyphenolic compounds that are commonly found in many species of medicinal plants from different families, i.e., Asteraceae, Lamiaceae, Rutaceae, and Passifloraceae [83, 84], with an estimated 10,000 species [85]. Structurally, they consist of two main groups: the 2-phenylchromans (flavonoids, including flavanones, flavones, flavonols, flavan-3-ols, and anthocyanidins) and the 3-phenylchromans (isoflavonoids, including isoflavones, isoflavans, and pterocarpans) [85]. Flavonoids have been extremely important for humanity. They have been strongly linked to health benefits of beverages like tea and wine, foods like fruits and vegetables, and extracts from medicinal plants [86].

The biological activity of flavonoids has a broad spectrum and thus they have been used extensively for their antiinflammatory, antilipidemic, antihyperglycemic, antiviral, hepatoprotective, gastric antiulcer, cardioprotective, neuroprotective, antioxidant, and anticancer properties [77]. Many studies have demonstrated a vast array of biochemical actions of flavonoids but the best-described property is their ability to act as antioxidants. It is well known that the antioxidant activity of flavonoids depends on the arrangement of functional groups with respect to the nuclear structure [84]. The protective effects of flavonoids are connected not only with their antioxidant but also vasodilatory actions [84]. Vascular endothelial function is considered as a marker in many cardiovascular problems, including hypertension $[87,88]$. Endothelium is known to regulate vascular tone by balancing vasoconstriction with vasodilation to provide adequate perfusion pressure to target organs. Moreover, endothelium interacts with leukocytes, thrombocytes, and vessel wall. It also synthesizes growth factors and thromboregulatory molecules and responds to physical and chemical signals [89]. Also, endothelium influences hemostatic balance between thrombosis and anticoagulation. Other functions include regulation of angiogenesis, wound healing, smooth muscle cell proliferation, fibrosis, and inflammation [88]. Therefore, endothelial dysfunction seems to have a complex relationship with hypertension preceding the development of pathological disorders in the cardiovascular system [87] while improvements in endothelial function could contribute to lower blood pressure. Not only numerous pharmacological studies but also clinical and epidemiological investigations have shown an inverse correlation between dietary flavonoid consumption and chronic degenerative diseases, such as cardiovascular diseases (CVD) [70, 90, 91]. Results of systematic reviews and meta-analysis of prospective cohort studies have shown that a high flavonoid intake is associated with lower mortality from CVD. These results are consistent with current recommendations for a healthy diet to increase consumption of fruits and vegetables, which contain meaningful level of flavonoids [91]. Yet, the exact role of flavonoids in the pathology of the cardiovascular system remains unclear, which should encourage further research in this field [92]. 
<smiles>O=c1c(O)c(-c2ccc(O)c(O)c2)oc2cc(O)cc(O)c12</smiles>

FIgURE 1: Chemical structure of quercetin.

\section{Quercetin: Natural Source, Influence during Pregnancy, In Vitro and In Vivo Pharmacological Activities, Clinical Trials, Safety Profile}

Quercetin $\left(3,3^{\prime}, 4^{\prime}, 5,7\right.$-pentahydroxyflavone) (Figure 1) is one of the most important representatives of flavonols, which is a subclass of flavonoids, and one of the most abundant flavonoids widely distributed in apples, berries, onions, tea, green vegetables, and herbs [93]. During the last years, several studies have reported beneficial effects of quercetin in cardiovascular diseases, such as hypertension, atherosclerosis, ischemia-reperfusion injury, or cardiotoxicity [78, 94, 95].

The mechanism of action of quercetin that is discussed below includes regulation of activity and structure of endothelial cells as well as anti-inflammatory and antioxidant properties, which are analyzed both in animal and human cell lines in models in vivo and in clinical trials. We believe that molecular and cellular mechanisms of action of quercetin may correspond with targets in PIH.

\section{Quercetin Intake during Pregnancy}

It is known that several flavonoids can cross the placenta and may be accumulated in fetal tissue $[96,97]$. It was found that quercetin affects pregnancy in animal model [97-103]. According to Vanhees et al., when female mice were exposed to quercetin (302 $\mathrm{mg} / \mathrm{kg}$ feed) from 3 days before conception until day 14.5 of gestation, no negative effects on placenta or fetal development were found [97]. An earlier study has shown that quercetin administrated to mice $(333 \mathrm{mg} / \mathrm{kg}$ feed) did not have any teratogenic effects on the fetus [98]. Exposure to quercetin during pregnancy resulted in upregulation of genes involved in enzymatic antioxidant defense system of the liver of fetuses at day 14.5 of gestation [97]. Recently, Khaksary-Mahabady et al. [103] have observed a protective effect of quercetin $(75 \mathrm{mg} / \mathrm{kg})$ on histomorphometric changes of kidneys of fetuses in pregnant rats treated with alltransretinoic acid (a teratogenic metabolite). Interestingly, Toumi et al. [104] have shown that besides a protective effect with respect to hematological and behavioral anomalies in traumatized pregnant rats, quercetin $(50 \mathrm{mg} / \mathrm{kg}$ per 6 days) may lastingly modulate behavior of their progeny. It was shown that quercetin administered prior to psychotraumatic stress alleviated signs of anxiety and hematological changes in pregnant rats without affecting the neonatal hematological status [104]. Moreover, it was demonstrated that a 6-week-quercetin treatment that started from day 3 postnatally improved significantly the memory ability of rats with hypoxic-ischemic brain damage [105]. A different study [99] has shown that quercetin reduced hydroxyurea-induced abnormal development of mouse embryos. Quercetin (66 $\mathrm{mg} / \mathrm{kg}$ supplemented diet) significantly improved fetal skeletal maldevelopment that was provoked with high saturated fat diet perhaps in part due to antioxidant effects of quercetin in placenta. Similarly, Sistani Karampour et al. [101] have observed preventive effects of quercetin on theophyllineinduced anomalies in embryos of pregnant female Wistar rats in groups where theophylline was used with quercetin (259 $\mathrm{mg} / \mathrm{kg}$, po and $100 \mathrm{mg} / \mathrm{kg}$, ip, respectively) on the 9th and 10th day of gestation. Quercetin improved heart conditions, reduced malondialdehyde levels, and elevated glutathione peroxidase activity [101]. Cytoprotective effects of quercetin were also observed in rat fetal liver in a study where [102] concentrations of malondialdehyde were lower and catalase, superoxide dismutase, and glutathione peroxidase enzyme activities were higher in the group treated with ciprofloxacin $(20 \mathrm{mg} / \mathrm{kg})$ plus quercetin $(20 \mathrm{mg} / \mathrm{kg})$ for 21 days compared to the group after ciprofloxacin alone. Mahabady and Varzi [103] studied the prophylactic effect of quercetin $(75 \mathrm{mg} / \mathrm{kg})$ on teratogenic effects of caffeine $(80 \mathrm{mg} / \mathrm{kg})$, which was given intraperitoneally at 9 th through 11th day of gestation of rats. It was observed that caffeine with quercetin significantly reduced incidence of cleft palate to $1.49 \%$ when compared to caffeine alone. The mean weight and length of animals' fetuses receiving quercetin were significantly increased when compared to other groups.

Zhao et al. [100] showed anti-abortive effect of quercetin in pregnant mice after injection of lipopolysaccharide (LPS). LPS induced embryo resorption in mice, while pretreatment with quercetin at a dose of $0.4 \mathrm{ml}$ at days 4 to 7 decreased the abortion rate to $50.0 \%$ through modulation of maternalfetal interface immunity balance, mainly by interleukin-10. In another study [106] it was observed that quercetin may inhibit proinflammatory cytokines production in pregnant mice, especially IL-6 and IL-8. Additionally, Braga et al. [107] investigated the effects of quercetin on the maternal reproductive capacity and fetal and placental development in diabetic rats. They showed that quercetin did not improve reproductive capacity, neither fetal nor placental development; however quercetin controlled glucose levels and promoted weight gain compared to untreated diabetic rats. Interestingly, it was observed in a different study [108] that quercetin at 10 $\mathrm{mg} / \mathrm{kg} /$ day affects uterine morphology but not proliferation. Yet, at doses of $100 \mathrm{mg} / \mathrm{kg} /$ day quercetin induced significant stromal and glandular proliferation, which could predispose the uterus towards neoplastic development.

Yet another study showed that quercetin had protective effect on the injured endometrial cells model obtained from pregnant rats (5.5 days of gestation). The treatment with quercetin $(50 \mu \mathrm{mol} / \mathrm{L}$ for $24 \mathrm{~h})$ increased expression of CYP1A1 and CYP2B1, as well as the contents of TNF- $\alpha, \mathrm{E}_{2}$, and IL-6 in the in vitro model [109]. 


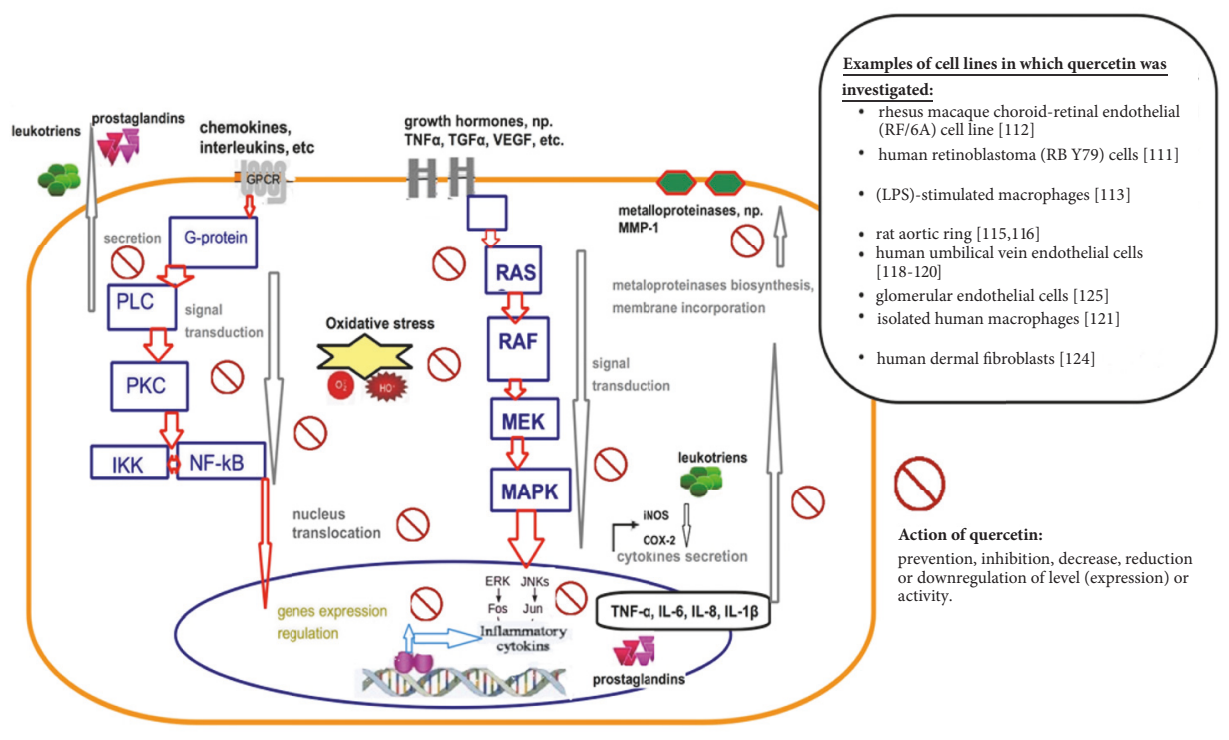

FIGURE 2: Examples of in vitro molecular action of quercetin (Q) in cited cellular experiments. Red arrows indicate the directions of interaction of intracellular proteins during signal transduction. Arrows marked in gray represent the direction of signaling in the cell or secretion beyond its expiration. The symbol of the swash in the wheel (red color) describes action of quercetin: prevention, inhibition, decrease, reduction, or downregulation of level (expression) or activity. Abbreviations: GPCR: G protein-coupled receptor; PLC: phospholipase C; PKC: protein kinase C; IKK: inhibitor of nuclear factor kappa-B kinase subunit beta; NF- $\kappa$ B: nuclear factor- $\kappa$ B; RAS, RAF, MEK, MAPK (p38 mitogenactivated protein kinase), ERK (extracellular signal-regulated kinase) pathway: Ras protein family members of small GTPases, involved in transmitting signals within cells (cellular signal transduction); Fos: protooncogenic transcription factor of the bZIP family, protooncogene; JUNKs (JNKs): c-Jun N-terminal kinases; Jun: one of the c-Jun N-terminal kinases; TNF- $\alpha$ : tumor necrosis factor $\alpha$; IL-6, IL-8, IL-1 $\beta$ : inflammatory interleukins; COX-2: cyclooxygenase-2; iNOS: inducible NO synthase.

\section{In Vitro Studies of Mechanism of Action}

7.1. Animal Cells. There are many studies that focus on anti-inflammatory activity of quercetin and its impact on growth factors in various in vitro models [109-112], which can be taken into account in therapy of pregnancy-induced hypertension (Figure 2). For example, Li et al. [112] showed that quercetin inhibited vascular endothelial growth factor (VEGF)-driven cell proliferation, migration, and tube formation of rhesus macaque choroid-retinal endothelial (RF/6A) cell line in a dose-dependent fashion: $22.7 \%, 31.5 \%$, and $36.7 \%$ inhibition when treated with 10,50 , and $100 \mu \mathrm{M}$ of quercetin, respectively. Similarly, Song et al. [111] observed that quercetin inhibited the expression of VEGFR in a dosedependent manner.

In a study on biomarkers of inflammatory process, quercetin was found to inhibit significantly the production of nitric oxide (NO), inducible NO synthase, interleukin-6, the nuclear translocation of nuclear factor $-\kappa \mathrm{B}(\mathrm{NF}-\kappa \mathrm{B})$, extracellular signal-regulated kinase $1 / 2($ Erk1/2), and c-Jun $\mathrm{N}$ terminal kinase (JNK) in LPS-stimulated macrophages [113]. Moreover, it inhibited MAPK/AP- 1 and IKK/NF- $\kappa$ B-induced inflammatory mediators [114]. Also, quercetin prevented angiotensin II-induced endothelial dysfunction [115] and inhibited protein kinase $\mathrm{C}$ activity and vascular superoxide production induced by endothelin-1 (in rat aortic ring) [116]. Moreover, Lee et al. [117] observed a protective effect of quercetin against arsenite-induced COX-2 expression (in rat liver epithelial cells).
7.2. Human Cells. Quercetin showed protective effects against inflammation in human umbilical vein endothelial cells via the downregulation of vascular cell adhesion molecule 1 (VCAM-1) [118]. Quercetin prevented lipid peroxidation induced by $\mathrm{H}_{2} \mathrm{O}_{2}$ and reduced the cytokineinduced cell-surface expression of VCAM-1 and E-selectin in cultured human endothelial cells $[119,120]$. Treating isolated human macrophages with quercetin reduced inflammation by attenuating gene expression for tumor necrosis factor $\alpha$ (TNF- $\alpha)$ and interleukins (IL-6, IL-8, IL-1 $\beta$ ) [121] and by inhibiting level of cyclooxygenase-2 (COX-2) and lipooxygenase (LOX) activities [122, 123]. Furthermore, the compound strongly inhibited induction of matrix metalloproteinase-1 (MMP-1, collagenase-1) and activation of extracellular signal-regulated protein kinase (ERK) and p38 mitogen-activated protein kinase (MAPK) (in human dermal fibroblasts) [124]. In glomerular endothelial cells, quercetin prevented asymmetric dimethylarginine (ADMA)induced renal fibrosis by reducing TGF- $\beta$ expression and ADMA-induced cell apoptosis mediated by the endoplasmic reticulum stress pathway [125].

\section{In Vivo Studies}

Several studies have stressed that quercetin showed free radical scavenger properties [126-128], which makes this flavonoid a well-established antioxidant that may be potentially used in prevention and treatment of cardiovascular disorders, even more as quercetin was reported to reduce 
oxidative damage to the brain, heart, and other tissues during ischemic reperfusion injury and exposure to compounds that induce oxidative stress $[102,129]$.

\section{Antihypertensive Activity of Quercetin In Vivo}

Quercetin has been shown to induce a progressive, dosedependent, and sustained reduction in blood pressure when given chronically in several rat models of experimental hypertension, including spontaneously hypertensive rats (SHR), rats with hypertension induced by inhibition of NO synthase with N-nitro-L-arginine methyl ester (L-NAME), deoxycorticosterone acetate (DOCA)-salt hypertensive rats, rat model of renovascular hypertension with reduced blood flow to one kidney, and rat genetic model of metabolic syndrome [23$35,130,131]$. Quercetin also prevented morphological and functional changes in the heart, vessels, and kidney [131]. The most important findings report that quercetin has fully reduced cytokine-stimulated expression of human C-reactive protein (CRP) and cardiovascular risk factors (murine serum amyloid A proteins, fibrinogen) in transgenic mice [98] and that it has led to decrease of inflammatory process in atopic dermatitis mouse model [114] and levels of TNF- $\alpha$, IL-1 $\beta$, IL17 , and MCP- 1 in collagen-induced arthritis in various animal models [132]. Recent studies are summarized in Table 1.

\section{Clinical Trials and Meta-Analysis}

Several human clinical trials have been conducted so far to estimate the efficacy of quercetin intake in the reduction of risk for hypertension and in hypertension treatment [3642]. Our literature review includes a recent meta-analysis of earlier clinical trials [43]. The Cochran collaboration did not perform comparative analysis of studies. The results are summarized in Table 2. A total of 7 clinical studies in which quercetin antihypertensive effect was estimated in adult patients $(\mathrm{n}=169)$ were included in this review paper. Quercetin was used in a range of doses from $162 \mathrm{mg} /$ day to $1095 \mathrm{mg}$ /day from 7 days to 6 weeks. Five double-blind controlled crossover clinical trials concluded that supplementary intake of quercetin was able to lower blood pressure of hypertensive patients [37-40, 42]. In contrast, two clinical trials showed no effect of quercetin supplementation on blood pressure [36, 41].

Results of meta-analysis of clinical trials [43] have shown that the impact of quercetin on blood pressure was reported in a total of 7 trials (587 patients) with results revealing significant reductions in both systolic and diastolic blood pressure following quercetin supplementation at doses from $100 \mathrm{mg} /$ day to $1000 \mathrm{mg} /$ day from 4 to 10 weeks $[93,107,133-$ 137]. In summary, the randomized controlled trials show that a significant reduction in systolic and diastolic blood pressure may be expected with quercetin doses $\geq 500 \mathrm{mg} /$ day and the effect is insignificant with doses $<500 \mathrm{mg} /$ day [43].

Proposed mechanism for such an effect of quercetin is still not completely understood but may include influence on the level of oxidative stress markers, endothelial function, vascular smooth muscle activity, modulation in cell signaling, and gene expression, which were all observed in some animal models [23, 25-28, 30, 31, 33, 34, 130]. Interestingly, in clinical trials, no reduction in stress markers was observed after quercetin administration, while in vitro quercetin showed such activity [36, 40, 42, 93]. Similarly, while quercetin has been shown to inhibit angiotensin-converting enzyme (ACE) function in vitro [138], clinical trials have observed no change in ACE activity [40]. Therefore, other targets and mechanisms of antihypertensive activity of quercetin should be considered.

Apart from chemical compounds obtained from natural sources, other active substances like acetylsalicylic acid (ASA) are candidates for consideration in the search for new pharmacological strategies for prevention and treatment of PIH. A systematic review and a meta-analysis showed that ASA treatment initiated early in pregnancy is an efficient method of reducing the incidence of PIH [139] and that low dose of ASA started in the first trimester in high-risk women may reduce the risk of PIH by up to 50\% [140]. Actually, aspirin at dose of $75 \mathrm{mg}$ is recommended by WHO [141] for the prevention of preeclampsia in women at high risk. However, randomized controlled clinical trials showed that aspirin initiated at $>16$ weeks of gestation was not associated with a risk reduction or a dose-response effect for severe PIH [142]. Moreover, a randomized placebo-controlled PREDO trial showed that aspirin at dose of $100 \mathrm{mg} /$ day caused no statistically significant effect in preventing preeclampsia in high-risk women [143]. On the other hand, a yet different multicenter randomized controlled study reports that aspirin use was associated with greater rates of vaginal bleeding and that an appropriately powered randomized controlled trial is now required to address the efficacy and safety of universal low-dose aspirin in low-risk pregnancy [144]. Based on these studies, it can be concluded that the search for an active drug with a higher safety index continues.

\section{Other Natural Compounds Tested}

Apigenin has recently gained attention as an alternative flavonoid compound for prevention and treatment of PIH. Previously, Manolescu [145] has observed that apigenin exhibited an endothelial nitric oxide synthase (eNOS) stimulation effect and was able to inhibit HIF- $1 \alpha$ expression as a factor causing placental hypoxia by blocking its interactions with HIF- $1 \alpha$-Hsp90 receptors. Recently, Hikmah et al. [146] have shown that an extract from Apium graveolens containing apigenin can prevent intrauterine growth restriction via suppression of antiangiogenic factors production in $\mathrm{PIH}$ animal model because it inhibited action of TNF $\alpha$ and HIF$1 \alpha$.

Besides, it was shown that polyphenolic compounds exert anti-inflammatory properties and provide protection to the endothelial cells. For this reason, polyphenols may give some insight into their usefulness in PIH. A polyphenolic extract from Theobroma cacao has been reported to increase cells viability and reduce interleukine- 6 and sVCAM-1 levels [147] as well as to increase nitric oxide and 


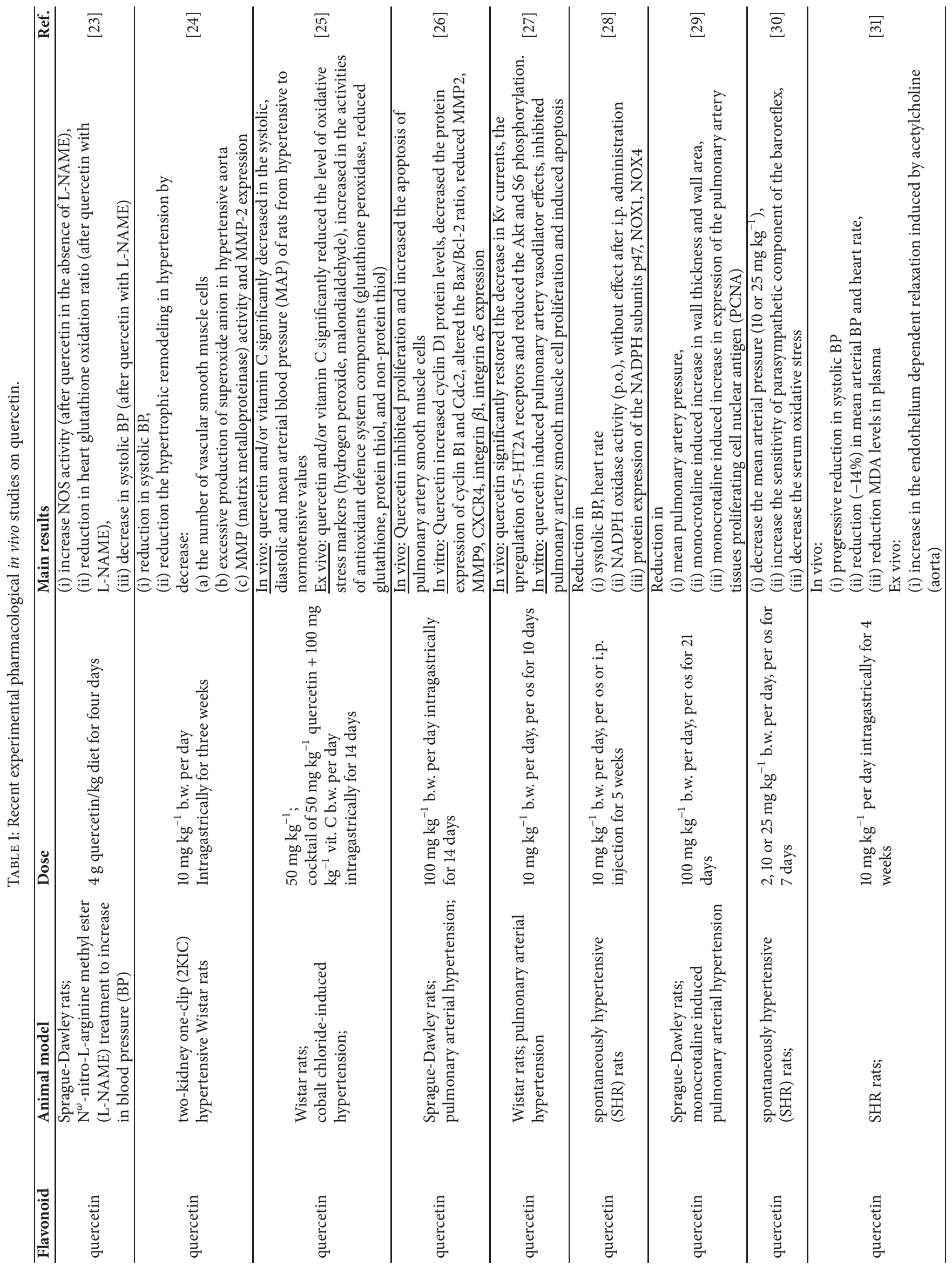




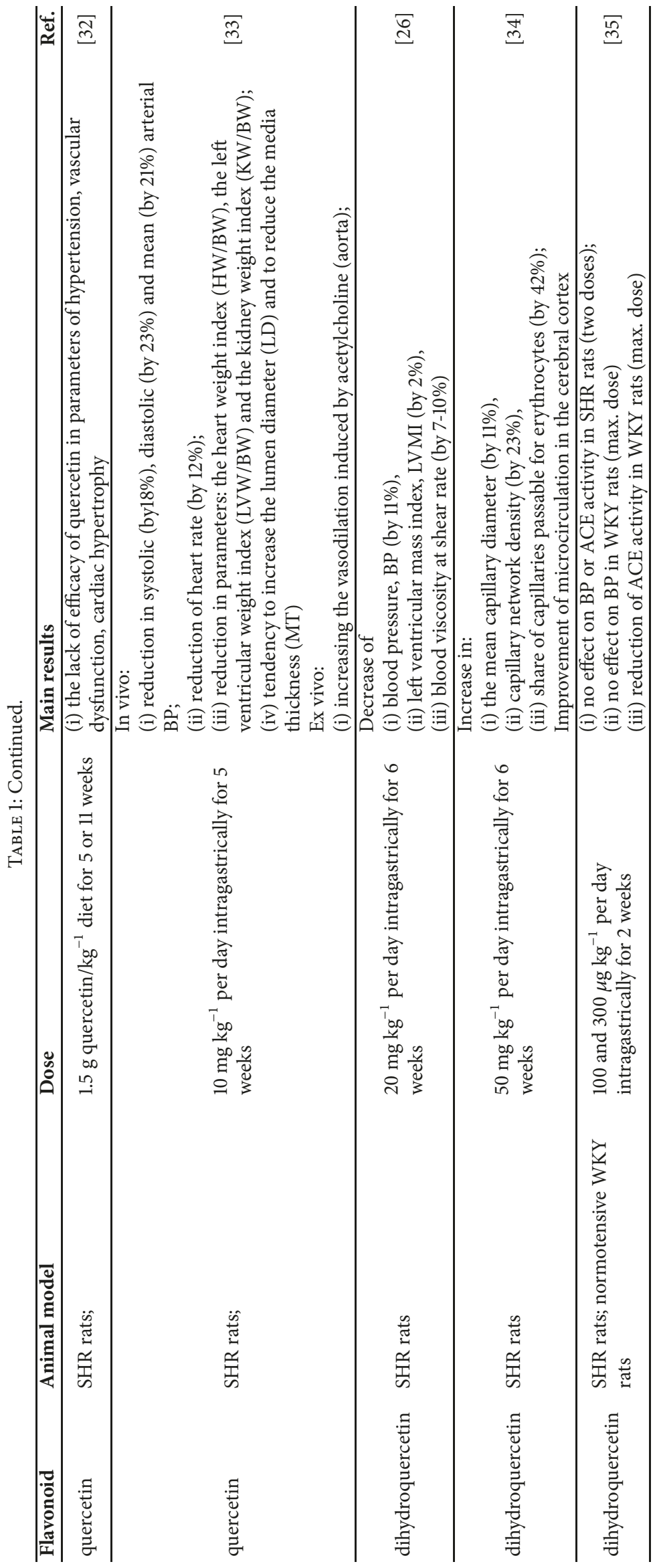




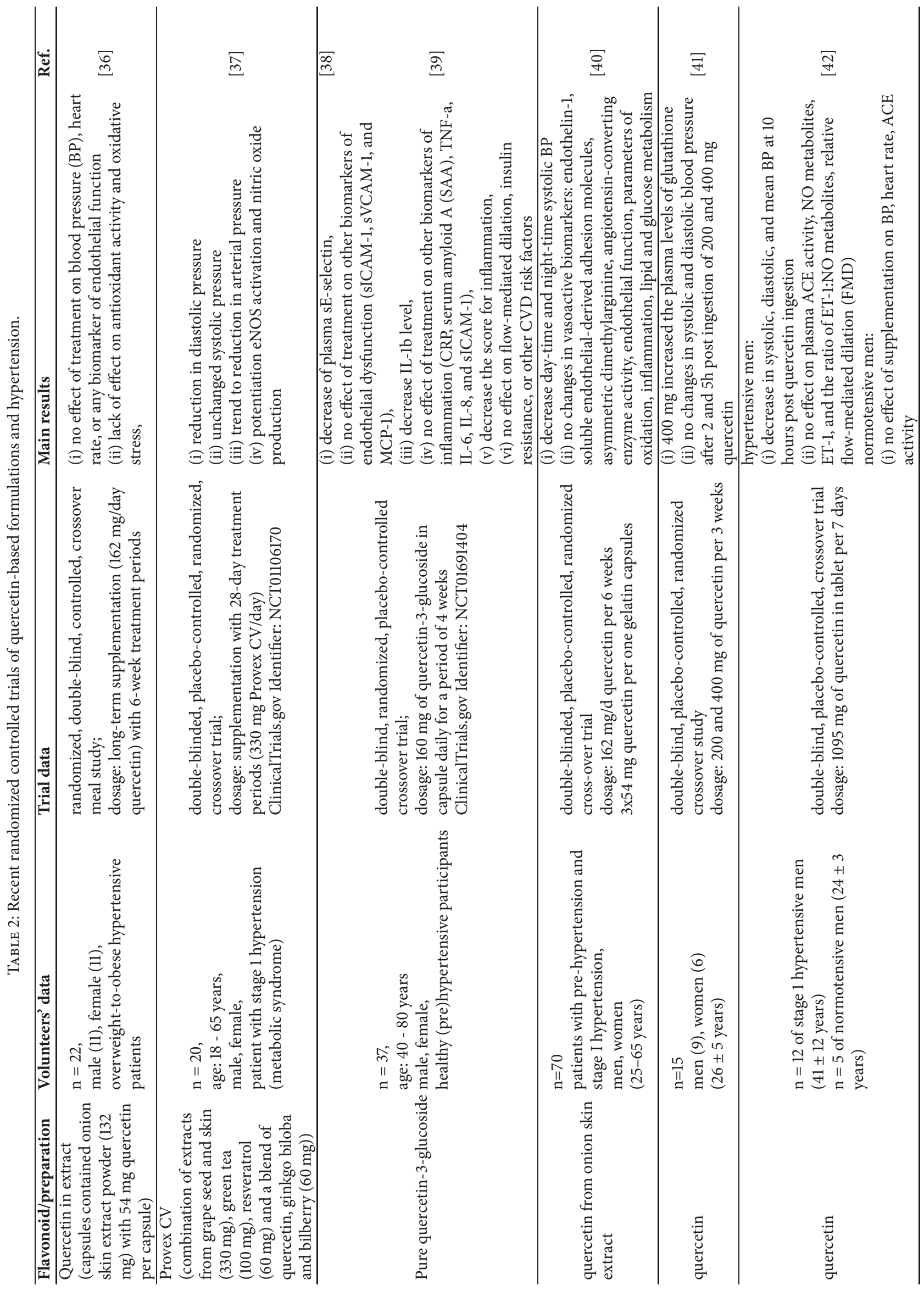




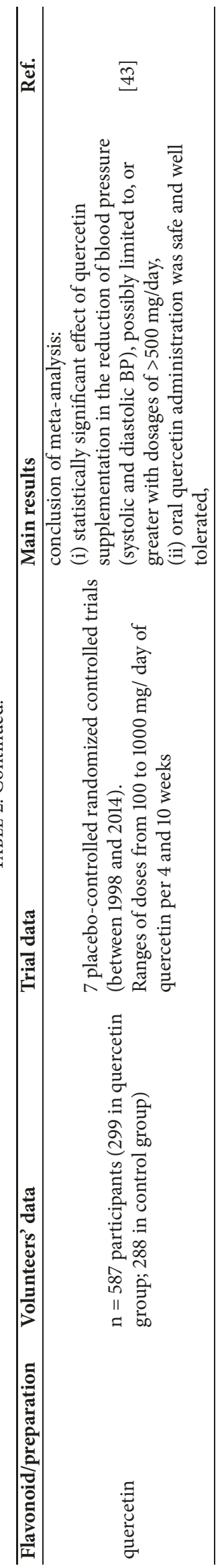


decrease endothelin-1 [148] in endothelial cells induced by plasma from PIH patients. Moreover, an extract of Punica granatum containing polyphenols (flavonoids and tannins) provided protection to the endothelial cells stimulated with severe PIH patients' plasma by suppressing production of proinflammatory cytokines (TNF-a and IL-6) and antiangiogenic factors (sFlt-1 and sEng) [149, 150]. Recently, a double-blind randomized and placebo-controlled clinical study showed that another polyphenolic compound, namely, epigallocatechin gallate (EGCG), increases the efficacy of nifedipine in patients with severe pregnancy-induced $\mathrm{PIH}$ [151]. Furthermore, an extract from Camellia sinensis (green tea) with polyphenols (catechins) showed anti-inflammatory properties during pregnancy of Wistar rats [152].

\section{Potential Problems with the Use of Quercetin}

Using quercetin as pharmacologic therapy in the form of dietary supplementation may encounter few problems. Firstly, bioavailability of quercetin is generally poor and it is affected by numerous factors [78, 153, 154]. Moreover, bioavailability of quercetin is very variable. Review of Harwood et al. [155] showed that in humans total plasma quercetin levels (i.e., quercetin, quercetin glycosides, glucuronides, and sulfates) between 29 and $248 \mathrm{ng} / \mathrm{ml}$ were attained following ingestion of a single meal consisting of quercetin-rich foods (50 mg quercetin). Another study showed that healthy subjects provided with $100 \mathrm{mg}$ of radiolabeled quercetin absorbed up to $53 \%$ of the total dose [156]. Quercetin dietary supplement formulations contain aglycone whereas food items contain mainly quercetin glycosides [157]. It is well known that after oral ingestion quercetin glycosides are physiologically hydrolyzed by glucosidases in the intestine and next quercetin aglycones passively diffuse through the intestinal epithelial barrier. However, quercetin glycosides may also be absorbed directly via the intestinal sodium-dependent glucose transporter-1 (SLGT1) [157, 158]. This type of absorption provides greater intestinal uptake of quercetin glucoside $[154,159]$. Both animal and human studies have shown that oral administration of quercetin yields as much as $60 \%$ of absorption [155]. It needs to be highlighted that the optimum intake of flavonoids from supplements has not been defined yet because a number of exogenous and endogenous factors modulating their bioavailability affect their vascular function [78]. Moreover, according to Terao [78] the low bioavailability of quercetin supplement may be partly attributed to its poor dispersion capacity in the digestive tract.

Presently, chemical modification of quercetin has led to new semisynthetic derivatives with improved bioavailability and solubility. These new compounds are still being investigated [160-162].

Another problem is that in the in vitro models it is the metabolites of quercetin that should be studied, not the parent compound. In human intestinal compartment quercetin is converted by phase II enzymes during the absorption process and, thus, it is the conjugated metabolites that are present in circulation [158]. Therefore, researchers should be focused on glucuronide/sulfate conjugates of quercetin when estimating their vascular effects using in vitro and in vivo models.

Extrapolating results from in vitro to in vivo is yet another problem as the heterogeneity of human organism cannot be simply replicated in vitro. Moreover, according to AvilaGalves et al., the use of a single cell line culture should be avoided [163]. The use of multiple cell lines with different features or different cell types in cocultures is postulated instead. Yet, such the procedure is far from easy. For this reason many studies have several limitations.

It was shown that quercetin is a multidrug resistance (MDR) modulator and thus it is a potential chemosensitizer as it can inhibit P-gp activity or it can decrease its expression and can interact with the ATP-binding site or the substratebinding site [164]. Consequently, on the basis of several studies, it should be realized that quercetin may interact with medicines such as anticancer drugs [165].

\section{In Vitro and In Vivo Toxicity and Drug Interaction}

According to International Agency for Research on Cancer of WHO [166] quercetin is not classifiable as to its carcinogenicity to humans (Group 3). Review of animal studies has shown that quercetin may increase drug bioavailability of many drugs including irinotecan, etoposide, tamoxifen, paclitaxel, doxorubicin (anticancer drugs), digoxin (drug used in heart failure), verapamil and diltiazem (calcium channel blockers used in the treatment of hypertension, angina pectoris, and some types of heart arrhythmia), valsartan (antihypertensive drug), ranolazine (drug to treat angina pectoris), and paracetamol [167].

\section{Safety Data from Clinical Trials}

Among the numerous published human intervention studies, adverse effects following supplemental quercetin intake have been rarely reported and any such effects were mild in nature [167]. So far no adverse events were reported in clinical trials where participants used quercetin at doses of $500 \mathrm{mg}$ per day for 4-8 weeks [137, 168], $730 \mathrm{mg}$ for 4 weeks [93], or $1000 \mathrm{mg}$ for 5 days, for at least 2 weeks or for 12 weeks [169]. Moreover, any adverse effects were associated with a single oral dose beyond $4 \mathrm{~g}$ [170]. After intake of $1000 \mathrm{mg}$ per day for $1 \mathrm{month}$ by patients with chronic pelvic pain syndrome, one patient developed headaches [171]. According to the US Food and Drug Administration quercetin has a generally recognized safe status (GRAS) [172]. Considering the seasonal supply of food extracts of flavonoids, the Recommended Dietary Allowance of total flavonoids might be between 250 and $400 \mathrm{mg} /$ day [173, 174]. However, in dietary supplements, recommended daily doses of quercetin aglycone usually reach up to $1000 \mathrm{mg}$ (most commonly $500 \mathrm{mg}$ ) [167].

Quercetin in humans caused a reduced bioavailability of midazolam (sedative) and talinolol (antihypertensive drug), and an increased bioavailability of cyclosporine, pravastatin 
(cholesterol-lowering drug), and fexofenadine (antihistamine drug) [167]. Furthermore, it is considered that patients with a kidney dysfunction may be a potential risk group for a long-term quercetin supplementation at high doses (potential nephrotoxic effects of quercetin) [167].

\section{Conclusion}

In summary, review of results of pharmacological studies shows that quercetin possesses antihypertensive activity via various mechanisms of action. While most studies have been carried out in in vitro and animal models, the antihypertensive mechanisms of quercetin in clinical studies remain somewhat elusive. Moreover, the influence of pure quercetin per se on pregnancy-induced hypertension has not been investigated. Nevertheless, various studies have shown that quercetin has a beneficial effect on vascular endothelial function and exhibits antioxidative and anti-inflammatory activity on cellular and tissue level. On the other hand, quercetin can affect the development of embryo, fetus, and placenta during pregnancy in animal model. Cytoprotective properties with regard to the fetus were observed in numerous studies. It was shown that quercetin did not have teratogenic and abortive effect on the fetus and it is generally recognized as safe.

All in all, these results allow formulating a proposition that quercetin be a new potential plant-origin drug in the treatment of PIH. Yet, for such potential to be realized, multilevel and complex pharmacological studies are needed. Future investigation should be focused on key factors among other inflammatory mediators and growth factors such as vascular endothelial growth factor, placental growth factor, and basic fibroblast growth factor, all involved in pathogenesis of pregnancy-induced hypertension.

\section{Conflicts of Interest}

The authors declare that they have no conflicts of interest.

\section{Acknowledgments}

This research was carried out within the framework of a research project no. 2017/25/B/NZ7/02741 financed by the National Science Center, Poland

\section{References}

[1] R. Townsend, P. O’Brien, and A. Khalil, "Current best practice in the management of hypertensive disorders in pregnancy," Integrated Blood Pressure Control, vol. 9, pp. 79-94, 2016.

[2] A. Mammaro, S. Carrara, A. Cavaliere et al., "Hypertensive Disorders of Pregnancy," Journal of Prenatal Medicine, vol. 3, no. 1, pp. 1-5, 2009.

[3] Pre-eclampsia, 2018/19 ICD-10-CM Codes, at: https://www .icd10data.com/ICD10CM/Codes/O00-O9A/O10-O16/O14.

[4] V. B. Luanni, E. Ota, G. Togoobaatar, M. Rintaro, and P. S. João, "Risk factors of pre-eclampsia/eclampsia and its adverse outcomes in low- and middleIncome countries: a WHO secondary analysis," PLoS ONE, vol. 9, no. 3, p. e91198, 2014.
[5] A. S. Fauci, E. Braunwald, and D. L. Kasper, "Disorders of intermediary metabolism," in Harrison's Principles of Internal Medicine, A. S. Fauci, E. Braunwald, and D. L. Kasper, Eds., pp. 2426-2429, McGraw-Hill, New York, NY, USA, 17th edition, 2008.

[6] S. Masoura, I. A. Kalogiannidis, G. Gitas et al., "Biomarkers in pre-eclampsia: A novel approach to early detection of the disease," Journal of Obstetrics \& Gynaecology, vol. 32, no. 7, pp. 609-616, 2012.

[7] L. Myatt and J. M. Roberts, "Preeclampsia: Syndrome or Disease?" Current Hypertension Reports, vol. 17, no. 11, article no. 83, 2015.

[8] M. Rehfeldt, E. Eklund, J. Struck et al., "Relaxin-2 connecting peptide (pro-RLX2) levels in second trimester serum samples to predict preeclampsia," Pregnancy Hypertension: An International Journal of Women's Cardiovascular Health, vol. 11, pp. 124128, 2018.

[9] C. Schaefer, P. Peters, and R. K. Miller, Drugs during Pregnancy and Lactation. Treatment Options and Risk Assessment, Elsevier, Oxford, UK, 2007.

[10] L. Myatt and R. P. Webster, "Is vascular biology in preeclampsia better?" Journal of Thrombosis and Haemostasis, vol. 7, no. 3, pp. 375-384, 2009.

[11] S. Middeldorp, "Pregnancy Failure and Heritable Thrombophilia," Seminars in Hematology, vol. 44, no. 2, pp. 93-97, 2007.

[12] S. Baumwell and S. A. Karumanchi, "Pre-eclampsia: clinical manifestations and molecular mechanisms," Nephron Clinical Practice, vol. 106, no. 2, pp. c72-c81, 2007.

[13] C. Fatini, E. Sticchi, F. Gensini et al., "Endothelial nitric oxide synthase gene influences the risk of pre-eclampsia, the recurrence of negative pregnancy events, and the maternal-fetal flow," Journal of Hypertension, vol. 24, no. 9, pp. 1823-1829, 2006.

[14] M. Napolitano, F. Miceli, A. Calce et al., "Expression and relationship between endothelin-1 messenger ribonucleic acid (mRNA) and inducible/endothelial nitric oxide synthase mRNA isoforms from normal and preeclamptic placentas," The Journal of Clinical Endocrinology \& Metabolism, vol. 85, no. 6, pp. 2318-2323, 2000.

[15] C. E. Powe, R. J. Levine, and S. A. Karumanchi, "Preeclampsia, a disease of the maternal endothelium: the role of antiangiogenic factors and implications for later cardiovascular disease," Circulation, vol. 123, no. 24, pp. 2856-2869, 2011.

[16] T. Tomimatsu, K. Mimura, M. Endo, K. Kumasawa, and T. Kimura, "Pathophysiology of preeclampsia: An angiogenic imbalance and long-lasting systemic vascular dysfunction," Hypertension Research, vol. 40, no. 4, pp. 305-310, 2017.

[17] T. Słowiński, H. Neumayer, T. Stolze, G. Gossing, H. Halle, and B. Hocher, "Endothelin system in normal and hypertensive pregnancy," Clinical Science, vol. 103, no. s2002, pp. 446S-449S, 2002.

[18] B. Baksu, I. Davas, A. Baksu, A. Akyol, and G. Gulbaba, "Plasma nitric oxide, endothelin-1 and urinary nitric oxide and cyclic guanosine monophosphate levels in hypertensive pregnant women," International Journal of Gynecology and Obstetrics, vol. 90, no. 2, pp. 112-117, 2005.

[19] L. M. Amaral, M. W. Cunningham, D. C. Cornelius, and B. LaMarca, "Preeclampsia: long-term consequences for vascular health," Vascular Health and Risk Management, vol. 11, pp. 403415, 2015.

[20] J. S. Possomato-Vieira and R. A. Khalil, "Mechanisms of Endothelial Dysfunction in Hypertensive Pregnancy and 
Preeclampsia," Advances in Pharmacology, vol. 77, pp. 361-431, 2016.

[21] B. Bakrania, J. Duncan, J. P. Warrington, and J. P. Granger, “The endothelin type a receptor as a potential therapeutic target in preeclampsia," International Journal of Molecular Sciences, vol. 18, no. 3, article 522, pp. 1-8, 2017.

[22] J. P. Granger, F. T. Spradley, and B. A. Bakrania, "The Endothelin System: A Critical Player in the Pathophysiology of Preeclampsia," Current Hypertension Reports, vol. 20, no. 4, 2018.

[23] V. Calabró, M. C. Litterio, C. G. Fraga, M. Galleano, and B. Piotrkowski, "Effects of quercetin on heart nitric oxide metabolism in 1 -NAME treated rats," Archives of Biochemistry and Biophysics, vol. 647, pp. 47-53, 2018.

[24] S. C. Pereira, J. M. Parente, V. A. Belo et al., "Quercetin decreases the activity of matrix metalloproteinase-2 and ameliorates vascular remodeling in renovascular hypertension," Atherosclerosis, vol. 270, pp. 146-153, 2018.

[25] T. O. Ajibade, A. A. Oyagbemi, T. O. Omobowale, E. R. Asenuga, and K. O. Adigun, "Quercetin and Vitamin C Mitigate Cobalt Chloride-Induced Hypertension through Reduction in Oxidative Stress and Nuclear Factor Kappa Beta (NF-Kb) Expression in Experimental Rat Model," Biological Trace Element Research, vol. 175, no. 2, pp. 347-359, 2017.

[26] M. B. Plotnikov, O. I. Aliev, A. V. Sidekhmenova et al., "Modes of Hypotensive Action of Dihydroquercetin in Arterial Hypertension," Bulletin of Experimental Biology and Medicine, vol. 162 , no. 3, pp. 353-356, 2017.

[27] D. Morales-Cano, C. Menendez, E. Moreno et al., "The flavonoid quercetin reverses pulmonary hypertension in rats," PLoS ONE, vol. 9, no. 12, Article ID el14492, 2014.

[28] P. Galindo, S. González-Manzano, M. J. Zarzuelo et al., "Different cardiovascular protective effects of quercetin administered orally or intraperitoneally in spontaneously hypertensive rats," Food \& Function, vol. 3, no. 6, pp. 643-650, 2012.

[29] H. Gao, C. Chen, S. Huang, and B. Li, "Quercetin attenuates the progression of monocrotaline-induced pulmonary hypertension in rats," Journal of Biomedical Research, vol. 26, no. 2, pp. 98-102, 2012.

[30] M. M. O. Monteiro, M. S. França-Silva, N. F. B. Alves, S. K. P. Porpino, and V. A. Braga, "Quercetin improves baroreflex sensitivity in spontaneously hypertensive rats," Molecules, vol. 17, no. 11, pp. 12997-13008, 2012.

[31] M. Romero, R. Jiménez, B. Hurtado et al., "Lack of beneficial metabolic effects of quercetin in adult spontaneously hypertensive rats," European Journal of Pharmacology, vol. 627, no. 1-3, pp. 242-250, 2010.

[32] J. Carlstrom, J. D. Symons, C. W. Tzu, R. S. Bruno, S. E. Litwin, and T. Jalili, "A quercetin supplemented diet does not prevent cardiovascular complications in spontaneously hypertensive rats," Journal of Nutrition, vol. 137, no. 3, pp. 628-633, 2007.

[33] J. Duarte, R. Pérez-Palencia, F. Vargas et al., "Antihypertensive effects of the flavonoid quercetin in spontaneously hypertensive rats," British Journal of Pharmacology, vol. 133, no. 1, pp. 117-124, 2001.

[34] M. B. Plotnikov, O. I. Aliev, A. M. Anishchenko, A. B. Sidekhmenova, A. Y. Shamanaev, and T. I. Fomina, "Parameters of cerebral cortex capillary network in SHR rats during the development of arterial hypertension and stable high blood pressure," Rossiiskii Fiziologicheskii Zhurnal, vol. 102, no. 5, pp. 558-566, 2016.

[35] G. A. Slashcheva, V. A. Rykov, A. V. Lobanov et al., "Dihydroquercetin Does Not Affect Age-Dependent Increase in Blood
Pressure and Angiotensin-Converting Enzyme Activity in the Aorta of Hypertensive Rats," Bulletin of Experimental Biology and Medicine, vol. 161, no. 5, pp. 670-673, 2016.

[36] V. Brüll, C. Burak, B. Stoffel-Wagner et al., "Acute intake of quercetin from onion skin extract does not influence postprandial blood pressure and endothelial function in overweightto-obese adults with hypertension: a randomized, doubleblind, placebo-controlled, crossover trial," European Journal of Nutrition, vol. 56, no. 3, pp. 1347-1357, 2017.

[37] S. Biesinger, H. A. Michaels, A. S. Quadros et al., "A combination of isolated phytochemicals and botanical extracts lowers diastolic blood pressure in a randomized controlled trial of hypertensive subjects," European Journal of Clinical Nutrition, vol. 70, no. 1, pp. 10-16, 2016.

[38] J. I. Dower, J. M. Geleijnse, L. Gijsbers, P. L. Zock, D. Kromhout, and P.C. H. Hollman, "Effects of the pure flavonoids epicatechin and quercetin on vascular function and cardiometabolic health: a randomized, double-blind, placebo-controlled, crossover trial," American Journal of Clinical Nutrition, vol. 101, no. 5, pp. 914-921, 2015.

[39] J. I. Dower, J. M. Geleijnse, L. Gijsbers, C. Schalkwijk, D. Kromhout, and P. C. Hollman, "Supplementation of the pure flavonoids epicatechin and quercetin affects some biomarkers of endothelial dysfunction and inflammation in (pre)hypertensive adults: a randomized double-blind, placebocontrolled, crossover trial," Journal of Nutrition, vol. 145, no. 7, pp. 1459-1463, 2015.

[40] V. Brüll, C. Burak, B. Stoffel-Wagner et al., "Effects of a quercetin-rich onion skin extract on $24 \mathrm{~h}$ ambulatory blood pressure and endothelial function in overweight-to-obese patients with (pre-)hypertension: a randomised double-blinded placebo-controlled cross-over trial," British Journal of Nutrition, vol. 114, no. 8, pp. 1263-1277, 2015.

[41] A. Perez, S. Gonzalez-Manzano, R. Jimenez et al., "The flavonoid quercetin induces acute vasodilator effects in healthy volunteers: Correlation with beta-glucuronidase activity," Pharmacological Research, vol. 89, pp. 11-18, 2014.

[42] A. Larson, M. A. H. Witman, Y. Guo et al., "Acute, quercetininduced reductions in blood pressure in hypertensive individuals are not secondary to lower plasma angiotensinconverting enzyme activity or endothelin-1: Nitric oxide," Nutrition Research, vol. 32, no. 8, pp. 557-564, 2012.

[43] M. C. Serban, A. Sahebkar, A. Zanchetti et al., "Lipid and blood pressure meta-analysis collaboration (LBPMC) group. Effects of quercetin on blood pressure: a systematic review and meta-analysis of randomized controlled trials," Journal of the American Heart Association, vol. 5, no. 7, pp. 10-1161, 2016.

[44] D. Draganovic, N. Lucic, D. Jojic, and S. Milicevic, "Correlation of oxidative stress markers with ultrasound and cardiotocography parameters with hypertension induced pregnancy," Acta Informatica Medica, vol. 25, no. 1, pp. 19-23, 2017.

[45] S. Bharadwaj, V. B. Bhat, V. Vickneswaran, B. Adhisivam, B. Zachariah, and S. Habeebullah, "Oxidative stress in preeclamptic mother-newborn dyads and its correlation with early neonatal outcome-a case control study," The Journal of Maternal-Fetal and Neonatal Medicine, vol. 31, no. 12, pp. 1548-1553, 2018.

[46] D. C. Cornelius, "Preeclampsia: From inflammation to immunoregulation," Clinical Medicine Insights: Blood Disorders, vol. 11, pp. 1-6, 2018.

[47] Y. Zhou, M. McMaster, K. Woo et al., "Vascular endothelial growth factor ligands and receptors that regulate human 
cytotrophoblast survival are dysregulated in severe preeclampsia and hemolysis, elevated liver enzymes, and low platelets syndrome," The American Journal of Pathology, vol. 160, no. 4, Article ID 62567, pp. 1405-1423, 2002.

[48] A. Liberis, G. Stanulov, E. Chafouz Ali, A. Hassan, A. Pagalos, and E. N. Kontomanolis, "Pre-eclampsia and the vascular endothelial growth factor: A new aspect," Clinical and Experimental Obstetrics \& Gynecology, vol. 43, no. 1, pp. 9-13, 2016.

[49] K. Chau, A. Hennessy, and A. Makris, "Placental growth factor and pre-eclampsia," Journal of Human Hypertension, vol. 31, no. 12, pp. 782-786, 2017.

[50] M. R. Hentschke, R. A. Ruszkowski, B. E. da Costa, and C. E. Poli-de-Figueiredo, "Placental growth factor and severity of preeclampsia: biomarkers, prediction of preeclampsia," Pregnancy Hypertension: An International Journal of Women's Cardiovascular Health, vol. 6, no. 3, p. 156, 2016.

[51] B. Manriquez Rocha, F. Mbofana, O. Loquiha et al., "Early diagnosis of preeclampsia using placental growth factor: An operational pilot study in Maputo, Mozambique," Pregnancy Hypertension: An International Journal of Women's Cardiovascular Health, vol. 11, pp. 26-31, 2018.

[52] B. Xu, S. Nakhla, A. Makris, and A. Hennessy, "TNF- $\alpha$ inhibits trophoblast integration into endothelial cellular networks," Placenta, vol. 32, no. 3, pp. 241-246, 2011.

[53] S. Smith, R. Francis, L. Guilbert, and P. N. Baker, "Growth factor rescue of cytokine mediated trophoblast apoptosis," Placenta, vol. 23, no. 4, pp. 322-330, 2002.

[54] B. A. G. Marwa, N. Raguema, H. Zitouni et al., "FGF1 and FGF2 mutations in preeclampsia and related features," Placenta, vol. 43, pp. 81-85, 2016.

[55] M. Hohlagschwandtner, M. Knöfler, M. Ploner, H. Zeisler, E. A. Joura, and P. Husslein, "Basic fibroblast growth factor and hypertensive disorders in pregnancy," Hypertension in Pregnancy, vol. 21, no. 3, pp. 235-241, 2002.

[56] G. K. Frampton, J. Jones, M. Rose, and L. Payne, "Placental growth factor (Alone or in combination with soluble fmslike tyrosine kinase 1) as an aid to the assessment of women with suspected pre-eclampsia: Systematic review and economic analysis," Health Technology Assessment, vol. 20, no. 87, pp. 1192, 2016.

[57] S. Duckworth, M. Griffin, P. T. Seed et al., "Diagnostic Biomarkers in Women with Suspected Preeclampsia in a Prospective Multicenter Study," Obstetrics \& Gynecology, vol. 128, no. 2, pp. 245-252, 2016.

[58] A. Kaluba-Skotarczak, J. Magiełda, A. Romała et al., "Importance of polymorphic variants of Tumour Necrosis Factor- $\alpha$ gene in the etiology of Intrauterine Growth Restriction," Ginekologia Polska, vol. 89, no. 3, pp. 160-168, 2018.

[59] S. A. Lowe and P. C. Rubin, "The pharmacological management of hypertension in pregnancy," Journal of Hypertension, vol. 10, no. 3, pp. 201-207, 1992.

[60] A. Seremak-Mrozikiewicz and K. Drews, "Methyldopa in therapy of hypertension in pregnant women," Ginekologia Polska, vol. 75, no. 2, pp. 160-165, 2004.

[61] A. Picaud, P. Walter, G. de Preville, and P. Nicolas, "Fatal toxic hepatitis in pregnancy. A discuss the role of methyldopa," Journal de Gynécologie Obstétrique et Biologie de la Reproduction, vol. 19, no. 2, pp. 192-161, 1990.

[62] B. M. Sibai, "Treatment of hypertension in pregnant women," The New England Journal of Medicine, vol. 335, no. 4, pp. 257265, 1996.
[63] A. R. Caton, E. M. Bell, C. M. Druschel et al., "Antihypertensive medication use during pregnancy and the risk of cardiovascular malformations," Hypertension, vol. 54, no. 1, pp. 63-70, 2009.

[64] R.-H. Xie, Y. Guo, D. Krewski et al., "Trends in using betablockers and methyldopa for hypertensive disorders during pregnancy in a Canadian population," European Journal of Obstetrics \& Gynecology and Reproductive Biology, vol. 171, no. 2, pp. 281-285, 2013.

[65] R. Adrover, "Hepatotoxicity from Alpha-Methyldopa During Pregnancy: Two Case Reports," Journal of Clinical Gastroenterology and Treatment, vol. 2, no. 3, 2016.

[66] Aldomet (methyldopa) side effects: https://www.rxlist.com/ aldomet-side-effects-drug-center.htm, 2018.

[67] F. A. Ghanem and A. Movahed, "Use of antihypertensive drugs during pregnancy and lactation," Cardiovascular Therapeutics, vol. 26, no. 1, pp. 38-49, 2008 .

[68] P. Singh, A. Mishra, S. Goswami, A. Singh, and K. D. Tiwari, "Hypertension and herbal plant for its treatment: a review," Indian Journal of Research in Pharmacy and Biotechnology, vol. 3, no. 5, pp. 358-366, 2015.

[69] J. Tomé-Carneiro and F. Visioli, "Polyphenol-based nutraceuticals for the prevention and treatment of cardiovascular disease: review of human evidence," Phytomedicine, vol. 23, no. 11, pp. 1145-1174, 2016.

[70] N. Schürger, E. Klein, A. Hapfelmeier, M. Kiechle, and D. Paepke, "Demand for integrative medicine among women in pregnancy and childbed: a German survey on patients' needs," BMC Complementary and Alternative Medicine, vol. 18, no. 1, p. 187, 2018.

[71] D. A. Kennedy, A. Lupattelli, G. Koren, and H. Nordeng, "Herbal medicine use in pregnancy: results of a multinational study," BMC Complementary and Alternative Medicine, vol. 13, no. 1, pp. 1-10, 2013.

[72] L. J. John and N. Shantakumari, "Herbal medicines use during pregnancy: A review from the middle east," Oman Medical Journal, vol. 30, no. 4, pp. 229-236, 2015.

[73] A. Akour, V. Kasabri, F. U. Afifi, and N. Bulatova, "The use of medicinal herbs in gynecological and pregnancy-related disorders by Jordanian women: a review of folkloric practice vs. evidence-based pharmacology," Pharmaceutical Biology, vol. 54, no. 9, pp. 1901-1918, 2016.

[74] A. B. Mekuria, D. A. Erku, B. M. Gebresillassie, E. M. Birru, B. Tizazu, and A. Ahmedin, "Prevalence and associated factors of herbal medicine use among pregnant women on antenatal care follow-up at University of Gondar referral and teaching hospital, Ethiopia: A cross-sectional study," BMC Complementary and Alternative Medicine, vol. 17, no. 1, 2017.

[75] J.-J. Dugoua, "Herbal medicines and pregnancy," Journal of Population Therapeutics and Clinical Pharmacology, vol. 17, no. 3, pp. e370-e378, 2010.

[76] L. O. Bruno, R. S. Simoes, M. de Jesus Simoes, M. J. B. C. Girão, and O. Grundmann, "Pregnancy and herbal medicines: An unnecessary risk for women's health-A narrative review," Phytotherapy Research, vol. 32, pp. 796-810, 2018.

[77] A. Mate, Ed., Medicinal and Aromatic Plants of the World. Scientific, Production, Commercial and Utilization Aspects, vol. 1, Springer Science + Business Media, Dordrecht, Netherlands, 2015.

[78] J. Terao, "Factors modulating bioavailability of quercetinrelated flavonoids and the consequences of their vascular function," Biochemical Pharmacology, vol. 139, pp. 15-23, 2017. 
[79] B. Romano, E. Pagano, V. Montanaro, A. L. Fortunato, N. Milic, and F. Borrelli, "Novel insights into the pharmacology of flavonoids," Phytotherapy Research, vol. 27, no. 11, pp. 1588-1596, 2013.

[80] M. Quiñones, M. Miguel, and A. Aleixandre, "Beneficial effects of polyphenols on cardiovascular disease," Pharmacological Research, vol. 68, no. 1, pp. 125-131, 2013.

[81] K. Yamagata, M. Tagami, and Y. Yamori, "Dietary polyphenols regulate endothelial function and prevent cardiovascular disease," Nutrition Journal , vol. 31, no. 1, pp. 28-37, 2015.

[82] J. L. D. B. Alves, V. P. de Sousa, M. P. C. Neto et al., "New insights on the use of dietary polyphenols or probiotics for the management of arterial hypertension," Frontiers in Physiology, vol. 7, no. 448, 2016.

[83] V. Emerenciano, J. Militão, C. Campos et al., "Flavonoids as chemotaxonomic markers for Asteraceae," Biochemical Systematics and Ecology, vol. 29, no. 9, pp. 947-957, 2001.

[84] S. Kumar and A. K. Pandey, "Chemistry and Biological Activities of Flavonoids: An Overview," The Scientific World Journal, vol. 2013, Article ID 162750, 16 pages, 2013.

[85] R. A. Dixon and G. M. Pasinetti, "Flavonoids and isoflavonoids: from plant biology to agriculture and neuroscience," Plant Physiology, vol. 154, no. 2, pp. 453-457, 2010.

[86] Ø. M. Andersen, K. R. Markham, and Chemistry. Flavonoids, Flavonoids. Chemistry, Biochemistry and Applications, CRC Press, Taylor \& Francis Group, Boca Raton, Fla, USA, 2006.

[87] K. Dharmashankar and M. E. Widlansky, "Vascular endothelial function and hypertension: insights and directions," Current Hypertension Reports, vol. 12, no. 6, pp. 448-455, 2010.

[88] R. J. Widmer and A. Lerman, "Endothelial dysfunction and cardiovascular disease," Global Cardiology Science Practice, vol. 2014, no. 3, pp. 291-308, 2014.

[89] D. Konukoglu and H. Uzun, "Endothelial dysfunction and hypertension," Advances in Experimental Medicine and Biology, vol. 956, pp. 511-540, 2016.

[90] S. Rastogi, M. M. Pandey, and A. K. S. Rawat, "Traditional herbs: a remedy for cardiovascular disorders," Phytomedicine, vol. 23, no. 11, pp. 1082-1089, 2016.

[91] Y. Kim and Y. Je, "Flavonoid intake and mortality from cardiovascular disease and all causes: A meta-analysis of prospective cohort studies," Clinical Nutrition ESPEN, vol. 20, pp. 68-77, 2017.

[92] S. Chirumbolo, "Flavonoids in coronary heart disease," Thrombosis Research, vol. 135, no. 5, pp. 1040-1041, 2015.

[93] R. L. Edwards, T. Lyon, S. E. Litwin, A. Rabovsky, J. D. Symons, and T. Jalili, "Quercetin reduces blood pressure in hypertensive subjects," Journal of Nutrition, vol. 137, no. 11, pp. 2405-2411, 2007.

[94] N. P. Bondonno, C. P. Bondonno, J. M. Hodgson, N. C. Ward, and K. D. Croft, "The Efficacy of Quercetin in Cardiovascular Health," Current Nutrition Reports, vol. 4, no. 4, pp. 290-303, 2015.

[95] J. G. Gormaz, S. Quintremil, and R. Rodrigo, "Cardiovascular disease: A target for the pharmacological effects of quercetin," Current Topics in Medicinal Chemistry, vol. 15, no. 17, pp. 17351742, 2015.

[96] E. Todaka, K. Sakurai, H. Fukata et al., "Fetal exposure to phytoestrogens - The difference in phytoestrogen status between mother and fetus," Environmental Research, vol. 99, no. 2, pp. 195-203, 2005.
[97] K. Vanhees, R. W. Godschalk, A. Sanders, S. B. Van Waalwijk van Doorn-Khosrovani, and F. J. Van Schooten, "Maternal quercetin intake during pregnancy results in an adapted iron homeostasis at adulthood," Toxicology, vol. 290, no. 2-3, pp. 351359, 2011.

[98] M. R. Prater, C. L. Laudermilch, C. Liang, and S. D. Holladay, "Placental Oxidative Stress Alters Expression of Murine Osteogenic Genes and Impairs Fetal Skeletal Formation," Placenta, vol. 29, no. 9, pp. 802-808, 2008.

[99] C. Liang, M. E. Oest, J. C. Jones, and M. R. Prater, "Gestational high saturated fat diet alters C57BL/6 mouse perinatal skeletal formation," Birth Defects Research Part B - Developmental and Reproductive Toxicology, vol. 86, no. 5, pp. 362-369, 2009.

[100] Y.-T. Zhao, X.-D. Wang, W.-Y. Shi, and X.-H. Zhong, "Antiabortive effect of quercetin and bornyl acetate on macrophages and IL-10 in uterus of mice," African Journal of Biotechnology, vol. 10, no. 43, pp. 8675-8682, 2010.

[101] N. S. Karampour, A. Arzi, H. N. Varzi, B. Mohammadian, and M. Rezaei, "Quercetin preventive effects on theophyllineinduced anomalies in rat embryo," Jundishapur Journal of Natural Pharmaceutical Products, vol. 9, no. 3, el7834, 2014.

[102] Z. Dogan, H. Elbe, E. Taslidere, H. Soysal, A. Cetin, and S. Demirtas, "Effects of ciprofloxacin on fetal rat liver during pregnancy and protective effects of quercetin," Biotechnic \& Histochemistry, vol. 92, no. 7, pp. 481-486, 2017.

[103] M. Khaksary-Mahabady, R. Ranjbar, H. Najafzadeh-Varzi, B. Mohammadian, and N. Gohari-Behbahani, "Protective effect of quercetin on histomorphometric changes in kidney of retinoid acid-treated rat fetuses," International Journal of Morphology, vol. 36, no. 1, pp. 338-344, 2018.

[104] M. L. Toumi, S. Merzoug, and A. Tahraoui, "Effects of quercetin on predator stress-related hematological and behavioural alterations in pregnant rats and their offspring," Journal of Biosciences, vol. 41, no. 2, pp. 237-249, 2016.

[105] J. J. Huang, X. Liu, X. Q. Wang, L. H. Yang, D. S. Qi, and R. Q. Yao, "Effects of quercetin on the learning and memory ability of neonatal rats with hypoxic-ischemic brain damage," Zhongguo Dang Dai Er Ke Za Zhi, vol. 146, pp. 454-457, 2012.

[106] W. Liu, M. Zhang, J. Feng, A. Fan, Y. Zhou, and Y. Xu, “The influence of quercetin on maternal immunity, oxidative stress, and inflammation in mice with exposure of fine particulate matter during gestation," International Journal of Environmental Research and Public Health, vol. 14, no. 592, pp. 1-16, 2017.

[107] C. P. Braga, R. d. Baptista, and F. B. Peixoto, "Effects of Quercetin Administration on the Pregnancy Outcome of Diabetic Rats," Journal of Diabetes \& Metabolism, vol. 03, no. 02, pp. 1-4, 2012.

[108] H. Shahzad, N. Giribabu, S. Muniandy, and N. Salleh, "Quercetin induces morphological and proliferative changes of rat's uteri under estrogen and progesterone influences," International Journal of Clinical and Experimental Pathology, vol. 7, no. 9, pp. 5484-5494, 2014.

[109] L. Xu, L. Sun, L. Lu, X. Zhong, Y. Ma, and J. Qin, "Effects of Quercetin on CYP450 and Cytokines in Aroclor 1254 Injured Endometrial Cells of the Pregnant Rats," BioMed Research International, vol. 2014, Article ID 497508, 7 pages, 2014.

[110] M. Lee, S. Yun, H. Lee, and J. Yang, "Quercetin Mitigates Inflammatory Responses Induced by Vascular Endothelial Growth Factor in Mouse Retinal Photoreceptor Cells through Suppression of Nuclear Factor Kappa B,' International Journal of Molecular Sciences, vol. 18, no. 11, p. 2497, 2017. 
[111] W. Song, X. Zhao, J. Xu, and H. Zhang, "Quercetin inhibits angiogenesis-mediated human retinoblastoma growth by targeting vascular endothelial growth factor receptor," Oncology Letters, vol. 14, no. 3, pp. 3343-3348, 2017.

[112] F. Li, Y. Bai, M. Zhao et al., "Quercetin inhibits vascular endothelial growth factor-induced choroidal and retinal angiogenesis in vitro," Ophthalmic Research, vol. 53, no. 3, pp. 109-116, 2015.

[113] H. N. Lee, S. A. Shin, G. S. Choo et al., "Anti-inflammatory effect of quercetin and galangin in LPS-stimulated RAW264.7 macrophages and DNCB-induced atopic dermatitis animal models," International Journal of Molecular Medicine, vol. 41, no. 2, pp. 888-898, 2018.

[114] M. Endale, S.-C. Park, S. Kim et al., "Quercetin disrupts tyrosine-phosphorylated phosphatidylinositol 3-kinase and myeloid differentiation factor- 88 association, and inhibits MAPK/AP- 1 and IKK/NF- $\kappa$ B-induced inflammatory mediators production in RAW 264.7 cells," Immunobiology, vol. 218, no. 12, pp. 1452-1467, 2013.

[115] M. Sanchez, F. Lodi, R. Vera et al., "Quercetin and isorhamnetin prevent endothelial dysfunction, superoxide production, and overexpression of p47phox induced by angiotensin II in rat aorta," Journal of Nutrition, vol. 137, no. 4, pp. 910-915, 2007.

[116] M. Romero, R. Jiménez, M. Sánchez et al., "Quercetin inhibits vascular superoxide production induced by endothelin-1: role of NADPH oxidase, uncoupled eNOS and PKC," Atherosclerosis, vol. 202, no. 1, pp. 58-67, 2009.

[117] K. M. Lee, M. K. Hwang, D. E. Lee, K. W. Lee, and H. J. Lee, "Protective effect of quercetin against arsenite-induced COX-2 expression by targeting PI3K in rat liver epithelial cells," Journal of Agricultural and Food Chemistry, vol. 58, no. 9, pp. 5815-5820, 2010.

[118] D. Yang, X. Liu, M. Liu, H. Chi, J. Liu, and H. Han, "Protective effects of quercetin and taraxasterol against $\mathrm{H} 2 \mathrm{O} 2$-induced human umbilical vein endothelial cell injury in vitro," Experimental and Therapeutic Medicine, vol. 10, no. 4, pp. 1253-1260, 2015.

[119] R. Kleemann, L. Verschuren, M. Morrison et al., "Antiinflammatory, anti-proliferative and anti-atherosclerotic effects of quercetin in human in vitro and in vivo models," Atherosclerosis, vol. 218, no. 1, pp. 44-52, 2011.

[120] I. Crespo, M. V. García-Mediavilla, B. Gutiérrez, S. SánchezCampos, M. J. Tuñón, and J. González-Gallego, "A comparison of the effects of kaempferol and quercetin on cytokine-induced pro-inflammatory status of cultured human endothelial cells," British Journal of Nutrition, vol. 100, no. 5, pp. 968-976, 2008.

[121] A. Overman, C.-C. Chuang, and M. McIntosh, "Quercetin attenuates inflammation in human macrophages and adipocytes exposed to macrophage-conditioned media," International Journal of Obesity, vol. 35, no. 9, pp. 1165-1172, 2011.

[122] H. P. Kim, I. Mani, L. Iversen, and V. A. Ziboh, "Effects of naturally-occurring flavonoids and biflavonoids on epidermal cyclooxygenase and lipoxygenase from guinea-pigs," Prostaglandins, Leukotrienes and Essential Fatty Acids, vol. 58, no. 1, pp. 17-24, 1998.

[123] Y. Li, J. Yao, C. Han et al., "Quercetin, inflammation and immunity," Nutrients, vol. 8, no. 3, article 167, 2016.

[124] H. Lim and P. K. Hyun, "Inhibition of mammalian collagenase, matrix metalloproteinase-1, by naturally-occurring flavonoids," Planta Medica, vol. 73, no. 12, pp. 1267-1274, 2007.
[125] W. Guo, J. Ding, A. Zhang et al., "The inhibitory effect of quercetin on asymmetric dimethylarginine-induced apoptosis is mediated by the endoplasmic reticulum stress pathway in glomerular endothelial cells," International Journal of Molecular Sciences, vol. 15, no. 1, pp. 484-503, 2014.

[126] S. F. Nabavi, S. M. Nabavi, M. Mirzaei, and A. H. Moghaddam, "Protective effect of quercetin against sodium fluoride induced oxidative stress in rat's heart," Food \& Function, vol. 3, no. 4, pp. 437-441, 2012.

[127] A. E. González-Esquivel, C. L. Charles-Niño, F. P. PachecoMoisés, G. G. Ortiz, F. Jaramillo-Juárez, and A. R. RincónSánchez, "Beneficial effects of quercetin on oxidative stress in liver and kidney induced by titanium dioxide (TiO ," Toxicology Mechanisms and Methods, vol. 25, no. 3, pp. 166-175, 2015.

[128] S. Kocahan, Z. Dogan, E. Erdemli, and E. Taskin, "Protective effect of quercetin against oxidative stress-induced toxicity associated with doxorubicin and cyclophosphamide in rat kidney and liver tissue," Iranian Journal of Kidney Diseases, vol. 11, no. 2, pp. 124-131, 2017.

[129] A.-C. V. Bayne and R. S. Sohal, "Effects of superoxide dismutase/catalase mimetics on life span and oxidative stress resistance in the housefly, Musca domestica," Free Radical Biology \& Medicine, vol. 32, no. 11, pp. 1229-1234, 2002.

[130] Y. He, X. Cao, X. Liu et al., "Quercetin reverses experimental pulmonary arterial hypertension by modulating the TrkA pathway," Experimental Cell Research, vol. 339, no. 1, pp. 122134, 2015

[131] F. Perez-Vizcaino, J. Duarte, R. Jimenez, C. Santos-Buelga, and A. Osuna, "Antihypertensive effects of the flavonoid quercetin," Pharmacological Reports, vol. 61, no. 1, pp. 67-75, 2009.

[132] N. Haleagrahara, S. Miranda-Hernandez, M. A. Alim, L. Hayes, G. Bird, and N. Ketheesan, "Therapeutic effect of quercetin in collagen-induced arthritis," Biomedicine \& Pharmacotherapy, vol. 90, pp. 38-46, 2017.

[133] J. A. Conquer, G. Maiani, E. Azzini, A. Raguzzini, and B. J. Holub, "Supplementation with quercetin markedly increases plasma quercetin concentration without effect on selected risk factors for heart disease in healthy subjects," Journal of Nutrition, vol. 128, no. 3, pp. 593-597, 1998.

[134] S. Egert, A. Bosy-Westphal, J. Seiberl et al., "Quercetin reduces systolic blood pressure and plasma oxidised lowdensity lipoprotein concentrations in overweight subjects with a high-cardiovascular disease risk phenotype: a double-blinded, placebo-controlled cross-over study," British Journal of Nutrition, vol. 102, no. 7, pp. 1065-1074, 2009.

[135] M. Pfeuffer, A. Auinger, U. Bley et al., "Effect of quercetin on traits of the metabolic syndrome, endothelial function and inflammation in men with different APOE isoforms," Nutrition, Metabolism \& Cardiovascular Diseases, vol. 23, no. 5, pp. 403409, 2013.

[136] M. Zahedi, R. Ghiasvand, A. Feizi, G. Asgari, and L. Darvish, "Does quercetin improve cardiovascular risk factors and inflammatory biomarkers in women with type 2 diabetes: a double-blind randomized controlled clinical trial," International Journal of Preventive Medicine, vol. 4, no. 7, pp. 777-785, 2013.

[137] F. Javadi, S. Eghtesadi, A. Ahmadzadeh et al., "The effect of quercetin on plasma oxidative status, C-reactive protein and blood pressure in women with rheumatoid arthritis," International Journal of Preventive Medicine, vol. 5, no. 3, pp. 293-301, 2014. 
[138] M. R. Loizzo, A. Said, R. Tundis et al., "Inhibition of angiotensin converting enzyme (ACE) by flavonoids isolated from Ailanthus excelsa (Roxb) (Simaroubaceae)," Phytotherapy Research, vol. 21, no. 1, pp. 32-36, 2007.

[139] E. Bujold, S. Roberge, Y. Lacasse et al., "Prevention of preeclampsia and intrauterine growth restriction with aspirin started in early pregnancy: a meta-analysis," Obstetrics \& Gynecology, vol. 116, no. 2, pp. 402-414, 2010.

[140] E. Bujold, A.-M. Morency, S. Roberge, Y. Lacasse, J.-C. Forest, and Y. Giguère, "Acetylsalicylic acid for the prevention of preeclampsia and intra-uterine growth restriction in women with abnormal uterine artery Doppler: a systematic review and meta-analysis," Journal of Obstetrics and Gynaecology Canada, vol. 31, no. 9, pp. 818-826, 2009.

[141] World Health Organization, “"WHO recommendations for prevention and treatment of pre-eclampsia and eclampsia," Geneva, 2011, ISBN 9789241548335.

[142] S. Roberge, K. Nicolaides, S. Demers, J. Hyett, N. Chaillet, and E. Bujold, "The role of aspirin dose on the prevention of preeclampsia and fetal growth restriction: systematic review and meta-analysis," American Journal of Obstetrics \& Gynecology, vol. 216, no. 2, pp. 110-120.e6, 2017.

[143] P. M. Villa, E. Kajantie, K. Räikkönen et al., "Aspirin in the prevention of pre-eclampsia in high-risk women: A randomised placebo-controlled PREDO Trial and a meta-analysis of randomised trials," BJOG: An International Journal of Obstetrics \& Gynaecology, vol. 120, no. 1, pp. 64-74, 2013.

[144] F. Mone, C. Mulcahy, P. McParland et al., BMJ Open, vol. 8, no. 7, p. e022056, 2018.

[145] B. Manolescu, E. Oprea, C. Busu, and C. Cercasov, "Natural compounds and the hypoxia-inducible factor (HIF) signalling pathway," Biochimie, vol. 91, no. 11-12, pp. 1347-1358, 2009.

[146] E. M. Hikmah and P. L. Widjiati, “Apium graveolens prevents itrauterine growth restriction via suppression of antiangiogenic factor production," Traditional Medicine Journal, vol. 23, no. 2, pp. 135-141, 2018.

[147] B. Rahayu, S. C. W. Baktiyani, and N. Nurdiana, "Theobroma cacao increases cells viability and reduces IL-6 and sVCAM-1 level in endothelial cells induced by plasma from preeclamptic patients," Pregnancy Hypertension: An International Journal of Women's Cardiovascular Health, vol. 6, no. 1, pp. 42-46, 2016.

[148] L. Barokah, S. C. W. Baktiyani, and U. Kalsum, "Protective effect of Theobroma cacao on nitric oxide and endothelin-1 level in endothelial cells induced by plasma from preeclamptic patients: In silico and in vitro studies," European Journal of Integrative Medicine, vol. 8, no. 1, pp. 73-78, 2016.

[149] D. Ambarwati, F. Fatmawati, M. Nooryanto, S. Santoso, S. C. Windu Baktiyani, and N. Nurdiana, "Punica granatum fruit extract inhibits the production of pro-inflammatory cytokines and angiogenic factors of HUVEC cells induced by plasma from patients with pre-eclampsia," Clinical Nutrition Experimental, vol. 15, pp. 9-14, 2017.

[150] I. Nasifah, S. Soeharto, and M. Nooryanto, "Effects of anti-lipid peroxidation of Punica granatum fruit extract in endothelial cells induced by plasma of severe pre-eclamptic patients," Journal of Ayurveda and Integrative Medicine, vol. 8, no. 4, pp. 215-217, 2017.

[151] D.-D. Shi, J.-J. Guo, L. Zhou, and N. Wang, "Epigallocatechin gallate enhances treatment efficacy of oral nifedipine against pregnancy-induced severe pre-eclampsia: A double-blind, randomized and placebo-controlled clinical study," Journal of
Clinical Pharmacy and Therapeutics, vol. 43, no. 1, pp. 21-25, 2018.

[152] A. C. Hachul, V. T. Boldarine, N. I. Neto et al., "Effect of the consumption of green tea extract during pregnancy and lactation on metabolism of mothers and 28d-old offspring," Scientific Reports, vol. 8, no. 1, pp. 1-7, 2018.

[153] X. Cai, Z. Fang, J. Dou, A. Yu, and G. Zhai, "Bioavailability of quercetin: Problems and promises," Current Medicinal Chemistry, vol. 20, no. 20, pp. 2572-2582, 2013.

[154] M. B. Kasikci and N. Bagdatlioglu, "Bioavailability of quercetin," Current Research in Nutrition and Food Science, vol. 4, no. 2, pp. 146-151, 2016.

[155] M. Harwood, B. Danielewska-Nikiel, J. F. Borzelleca, G. W. Flamm, G. M. Williams, and T. C. Lines, "A critical review of the data related to the safety of quercetin and lack of evidence of in vivo toxicity, including lack of genotoxic/carcinogenic properties," Food and Chemical Toxicology, vol. 45, no. 11, pp. 2179-2205, 2007.

[156] T. Walle, U. K. Walle, and P. V. Halushka, "Carbon dioxide is the major metabolite of quercetin in humans," Journal of Nutrition, vol. 131, no. 10, pp. 2648-2652, 2001.

[157] S. Andres, S. Pevny, R. Ziegenhagen et al., "Safety aspects of the use of quercetin as a dietary supplement," Molecular Nutrition Food Research, vol. 62, no. 1, pp. 10-1002, 2018.

[158] K. Murota and J. Terao, "Antioxidative flavonoid quercetin: implication of its intestinal absorption and metabolism," Archives of Biochemistry and Biophysics, vol. 417, no. 1, pp. 1217, 2003.

[159] Y. Guo and R. S. Bruno, "Endogenous and exogenous mediators of quercetin bioavailability," The Journal of Nutritional Biochemistry, vol. 26, no. 3, pp. 201-210, 2015.

[160] P. Zizkova, M. Stefek, L. Rackova, M. Prnova, and L. Horakova, "Novel quercetin derivatives: from redox properties to promising treatment of oxidative stress related diseases," ChemicoBiological Interactions, vol. 265, pp. 36-46, 2017.

[161] F. Grande, O. I. Parisi, R. A. Mordocco et al., "Quercetin derivatives as novel antihypertensive agents: Synthesis and physiological characterization," European Journal of Pharmaceutical Sciences, vol. 82, pp. 161-170, 2016.

[162] M. Lesjak, I. Beara, N. Simin et al., "Antioxidant and antiinflammatory activities of quercetin and its derivatives," Journal of Functional Foods, vol. 40, pp. 68-75, 2018.

[163] M. Á. Ávila-Gálvez, A. González-Sarrías, and J. C. Espín, “In vitro research on dietary polyphenols and health: a call of caution and a guide on how to proceed," Journal of Agricultural and Food Chemistry, vol. 66, no. 30, pp. 7857-7858, 2018.

[164] C. Chen, J. Zhou, and C. Ji, "Quercetin: A potential drug to reverse multidrug resistance," Life Sciences, vol. 87, no. 11-12, pp. 333-338, 2010.

[165] Z. Chen, C. Huang, T. Ma et al., "Reversal effect of quercetin on multidrug resistance via FZD7/ $\beta$-catenin pathway in hepatocellular carcinoma cells," Phytomedicine, vol. 43, pp. 37-45, 2018.

[166] IARC, "Monographs on the evaluation of the carcinogenic risk of chemicals to humans. Geneva. World Health Organization," International Agency for Research on Cancer, vol. 73, pp. 119, 1999, https://monographs.iarc.fr/iarc-monographs-on-theevaluation-of-carcinogenic-risks-to-humans-48/.

[167] S. Andres, S. Pevny, R. Ziegenhagen et al., "Safety Aspects of the Use of Quercetin as a Dietary Supplement," Molecular Nutrition \& Food Research, vol. 62, no. 1, pp. 1-15, 2018. 
[168] Y. Shi and G. Williamson, "Quercetin lowers plasma uric acid in pre-hyperuricaemic males: A randomised, doubleblinded, placebo-controlled, cross-over trial," British Journal of Nutrition, vol. 115, no. 5, pp. 800-806, 2016.

[169] F. Jin, D. C. Nieman, R. A. Shanely, A. M. Knab, M. D. Austin, and W. Sha, "The variable plasma quercetin response to 12week quercetin supplementation in humans," European Journal of Clinical Nutrition, vol. 64, no. 7, pp. 692-697, 2010.

[170] M. Russo, C. Spagnuolo, I. Tedesco, S. Bilotto, and G. L. Russo, "The flavonoid quercetin in disease prevention and therapy: facts and fancies," Biochemical Pharmacology, vol. 83, no. 1, pp. 6-15, 2012.

[171] D. A. Shoskes, S. I. Zeitlin, A. Shahed, and J. Rajfer, "Quercetin in men with category III chronic prostatitis: a preliminary prospective, double-blind, placebo-controlled trial," Urology, vol. 54, no. 6, pp. 960-963, 1999.

[172] "FDA (U.S. Food and Drug Administration), Agency response letter GRAS notice no. GRN 000341," 2010, https://www.fda .gov/Food/IngredientsPackagingLabeling/GRAS/NoticeInventory/ucm235935.htm.

[173] I. Peluso, A. Raguzzini, and M. Serafini, "Effect of flavonoids on circulating levels of TNF- $\alpha$ and IL- 6 in humans: a systematic review and meta-analysis," Molecular Nutrition \& Food Research, vol. 57, no. 5, pp. 784-801, 2013.

[174] I. Peluso and M. Palmery, "Flavonoids at the pharma-nutrition interface: Is a therapeutic index in demand?" Biomedicine \& Pharmacotherapy, vol. 71, pp. 102-107, 2015. 


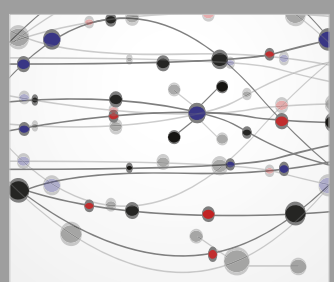

The Scientific World Journal
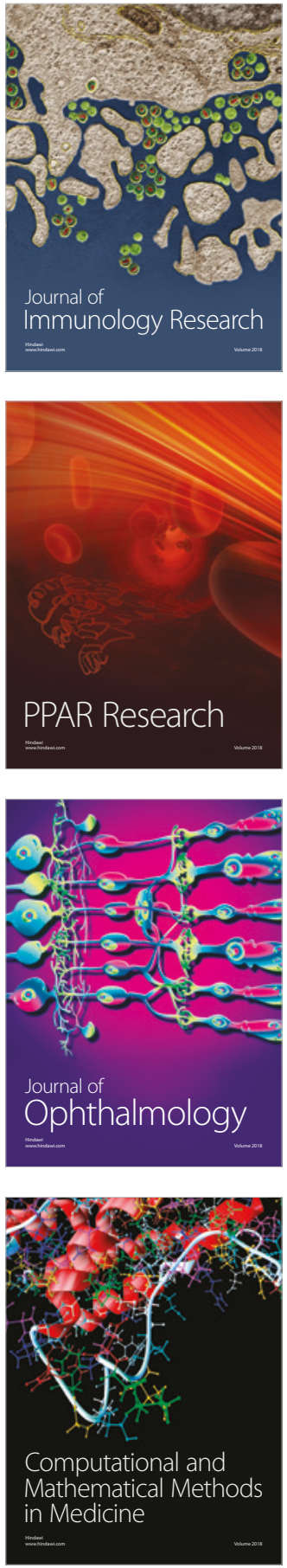

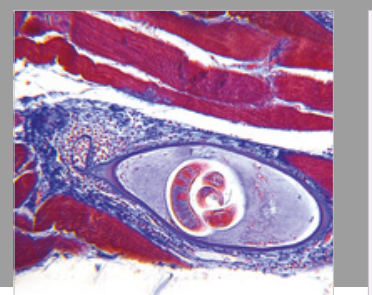

Gastroenterology Research and Practice

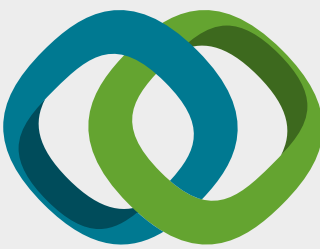

\section{Hindawi}

Submit your manuscripts at

www.hindawi.com
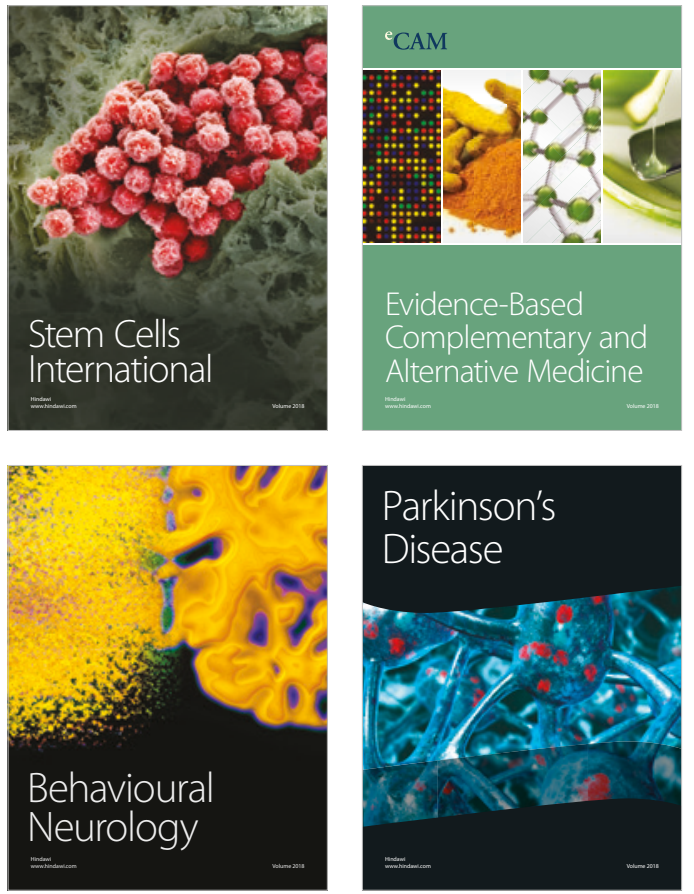

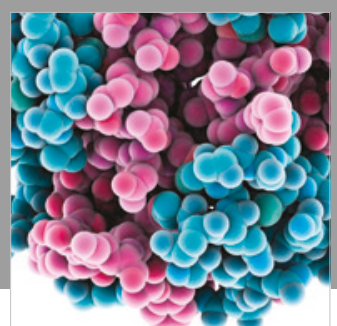

ournal of

Diabetes Research

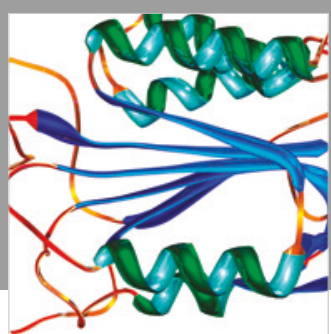

Disease Markers
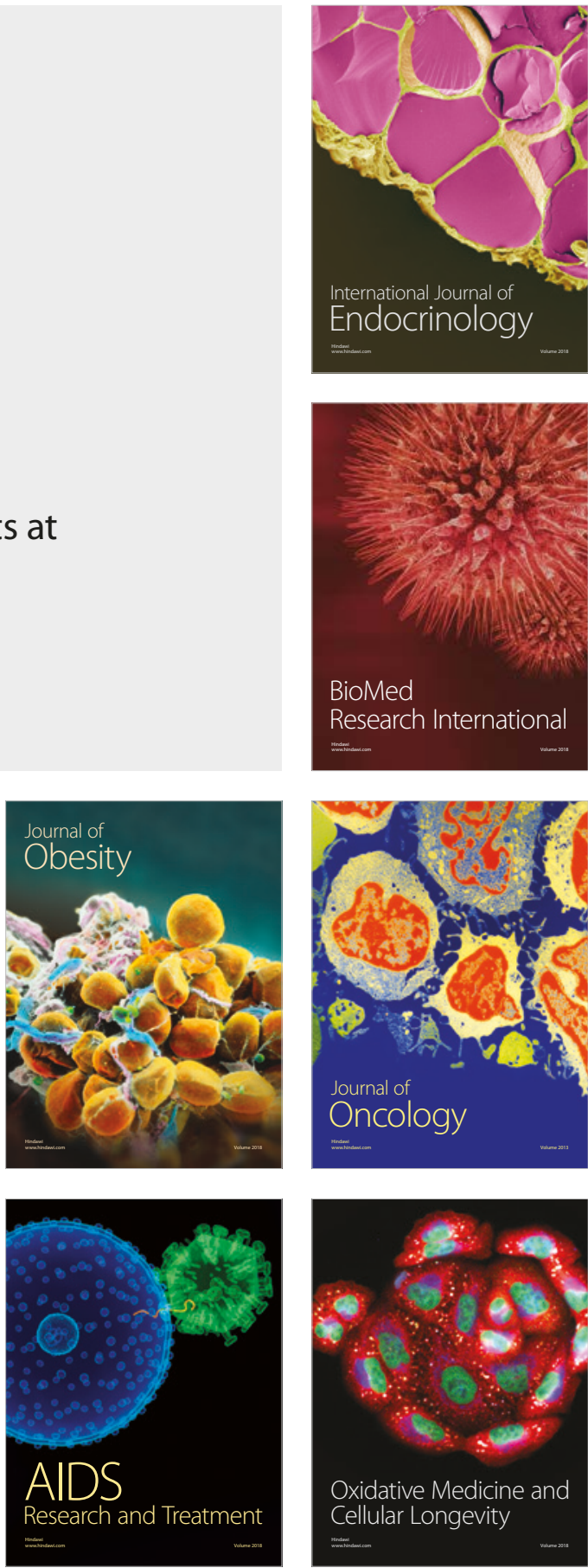